ARTICLE

\title{
Immunoglobulin expression and the humoral immune response is regulated by the non-canonical poly(A) polymerase TENT5C
}

\author{
Aleksandra Bilska (1) 1,9, Monika Kusio-Kobiałka1,2,9, Paweł S. Krawczyk (1) 2,3, Olga Gewartowska ${ }^{2,3}$, \\ Bartosz Tarkowski 2,3, Kamil Kobyłecki², Dominika Nowis (1) 4,5, Jakub Golab (1) 6,7, Jakub Gruchota ${ }^{2,3}$, \\ Ewa Borsuk ${ }^{2,3,8}$, Andrzej Dziembowski (iD ${ }^{1,2,3 凶}$ \& Seweryn Mroczek (iD) 1,3凶
}

TENT5C is a non-canonical cytoplasmic poly(A) polymerase highly expressed by activated $B$ cells to suppress their proliferation. Here we measure the global distribution of poly $(A)$ tail lengths in responsive $B$ cells using a Nanopore direct RNA-sequencing approach, showing that TENT5C polyadenylates immunoglobulin mRNAs regulating their half-life and consequently steady-state levels. TENT5C is upregulated in differentiating plasma cells by innate signaling. Compared with wild-type, Tent $5 \mathrm{c}^{-/-}$mice produce fewer antibodies and have diminished T-cell-independent immune response despite having more CD138 high plasma cells as a consequence of accelerated differentiation. B cells from Tent5c $\mathrm{c}^{-/-}$mice also have impaired capacity of the secretory pathway, with reduced ER volume and unfolded protein response. Importantly, these functions of TENT5C are dependent on its enzymatic activity as catalytic mutation knock-in mice display the same defect as Tent $5 \mathrm{c}^{-/-}$. These findings define the role of the TENT5C enzyme in the humoral immune response.

\footnotetext{
${ }^{1}$ Institute of Genetics and Biotechnology, Faculty of Biology, University of Warsaw, Pawinskiego 5a, 02-106 Warsaw, Poland. ${ }^{2}$ Institute of Biochemistry and Biophysics, Polish Academy of Sciences, Pawinskiego 5a, 02-106 Warsaw, Poland. ${ }^{3}$ Laboratory of RNA Biology, International Institute of Molecular and Cell Biology, Trojdena 4, 02-109 Warsaw, Poland. ${ }^{4}$ Genomic Medicine, Medical University of Warsaw, Banacha 1a, 02-097 Warsaw, Poland. ${ }^{5}$ Laboratory of Experimental Medicine, Center of New Technologies, University of Warsaw, Banacha 2c, 02-097 Warsaw, Poland. ${ }^{6}$ Department of Immunology, Medical University of Warsaw, Banacha 1a, 02-097 Warsaw, Poland. ${ }^{7}$ Centre of Preclinical Research, Medical University of Warsaw, Banacha 1a, 02-097 Warsaw, Poland. ${ }^{8}$ Department of Embryology, Institute of Zoology, Faculty of Biology, University of Warsaw, Miecznikowa 1, 02-096 Warsaw, Poland.

${ }^{9}$ These authors contributed equally: Aleksandra Bilska, Monika Kusio-Kobiałka. ${ }^{凶}$ email: adziembowski@iimcb.gov.pl; seweryn.mroczek@gmail.com
} 
T he development of an adaptive humoral immune response requires the activation of resting $B$ cells following antigen recognition. This process is associated with structural and functional changes leading to the generation of high-affinity memory B cells and antibody-secreting plasma cells (ASC). Extensive B cell differentiation is characterized by the clonal expansion, somatic hypermutation leading to affinity maturation, isotype switching, and formation of ASC or memory cells. At a cellular level, this process involves the reorganization of the rough endoplasmic reticulum (RER) and Golgi compartments to promote immunoglobulin (Ig) synthesis, assembly, and secretion ${ }^{1,2}$. These global physiological changes occurring during B cell activation and differentiation are linked to broad changes in the transcriptomic profile, which is controlled by the coordinated action of regulatory networks of transcriptional factors, such as NF- $\mathrm{BB}, \mathrm{BCL6}$, IRF4, and BLIMP1 ${ }^{3}$. Studies have also shown the involvement of RNA-binding proteins and microRNAs in shaping the B cell transcriptome $e^{4,5}$, suggesting that posttranscriptional gene expression regulation plays an important role in B cell physiology ${ }^{6-9}$. In addition to global transcript changes, B cell maturation is associated with a large increase in the translation of mRNAs targeted to the $\mathrm{ER}^{1,10}$.

Almost every mRNA molecule, except histone mRNAs, is polyadenylated during 3 '-end processing. Nuclear polyadenylation is mediated by canonical poly(A) polymerases that interact with 3 '-end cleavage machinery. The poly(A) tail has a critical function in mRNA stability and translation efficacy as nearly all mRNA decay pathways begin with the removal of poly(A) tails ${ }^{11-13}$. Previous studies of polyadenylation in $\mathrm{B}$ cells have focused on alternative polyadenylation and splicing in the regulation of Ig class switching ${ }^{14-17}$. However, in addition to the polyadenylation that occurs in the nucleus, the poly $(\mathrm{A})$ tail can be expanded in the cytoplasm by non-canonical poly(A) polymerases (ncPAPs). This process is considered to have an important function in the activation of dormant deadenylated mRNAs during gametogenesis ${ }^{18}$ and in neuronal processes, but has not been studied in B cells. We and others have identified a metazoan-specific family of cytoplasmic poly(A) polymerases, TENT5 (previously known as FAM46) ${ }^{19-21}$. In mammals, this family has four members, among which TENT5C is the best characterized. The importance of TENT5C is underscored by the occurrence of Tent5c somatic mutations in $20 \%$ of cases of multiple myeloma (MM) patients. Further work revealed that TENT5C is a bona fide MM cell growth suppressor ${ }^{21,22}$. TENT5C polyadenylates multiple mRNAs with a strong specificity to those encoding ER-targeted proteins. This partially explains TENT5C toxicity to MM cells since an increased protein load caused by the stabilization of ER-targeted mRNAs enhances the ER stress, to which $\mathrm{MM}$ is very sensitive. Initial characterization of Tent5c knockout (KO) in mice revealed that it might play a role in the physiology of normal B cells, since isolated primary splenocytes from Tent5c KO mice proliferate faster upon activation than those isolated from wild-type (WT) animals ${ }^{21,22}$.

Here, we show the role of TENT5C in B cells in more detail. Using Nanopore direct RNA sequencing, we provide global analysis of poly(A) tail distribution in B cells from WT and Tent $5 \mathrm{c}$ KO animals, and show that the primary targets of TENT5C are mRNAs encoding Igs. mRNAs encoding all classes of Ig have shorter poly(A) tails. Importantly, further studies indicate that the production of Igs is lower in Tent $5 \mathrm{c} \mathrm{KO} B$ cells, leading to decreased gamma globulin concentrations in $\mathrm{KO}$ mice serum and diminished humoral responses after immunization with thymus-independent (TI) antigens. TENT5C-deficient cells are characterized by accelerated growth rate and faster differentiation to $\mathrm{CD} 138^{\text {high }}$ plasma cells (PCs), which explains the increased number of these cells in the bone marrow (BM) and spleen of KO mice. Accordingly, TENT5C expression is limited to late stages of $\mathrm{B}$ cell lineage differentiation and is highly upregulated by innate signaling via specific Toll-like receptors (TLRs). Despite the acceleration of $\mathrm{B}$ cell proliferation rate, a lack of TENT5C results in a decreased ER compartment volume, reduced dynamics of its expansion during B cell activation, and downregulation of unfolded protein response (UPR). All these phenotypes are reproduced in mice expressing catalytically dormant TENT5C (D90N, D92N), which confirms that they result from the enzymatic activity of this ncPAP. In aggregate, here we show that cytoplasmic polyadenylation by ncPAP TENT5C regulates the humoral immune response.

\section{Results}

Ig mRNAs are specific TENT5C targets. TENT5C is implicated in the polyadenylation of mRNAs encoding proteins passing through the ER in MM cells, which originate from terminally differentiated B cells ${ }^{21}$. In order to identify TENT5C substrates in activated B cells, we implemented Oxford Nanopore Technologies (ONT) direct full-length RNA sequencing to measure poly (A) tail length at a genome-wide scale. Unlike traditional RNAseq techniques, the Nanopore-based system detects DNA or RNA single molecules as they traverse through protein channels, without the need for an enzymatic synthesis reaction. Moreover, despite higher per-base error-rate, this sequencing strategy avoids limitations and biases introduced during the amplification of long homopolymers, such as adenine tracts within poly(A) tails as PCR amplification of $\mathrm{CDNA}$ is not required during library preparation $^{23,24}$ (Fig. 1a). In the case of RNA sequencing, the substrate is a whole single RNA molecule with the motor protein attached to its 3 '-end, which passes the RNA strand through the pore at a consistent rate in an ATP-dependent manner. As the sequencing proceeds in the $3^{\prime}$ to $5^{\prime}$-direction, the adaptor oligo is detected first, followed by the poly(A) tail, then the entire body of the transcript is sequenced. For efficient sequencing, pure mRNA fractions are needed, and to avoid any biases total RNA was subjected to an mRNA enrichment step using the mutated recombinant elongation initiation factor $4 \mathrm{E}\left(\mathrm{GST}-\mathrm{eIF} 4 \mathrm{E}^{\mathrm{K} 119 \mathrm{~A}}\right)$, which has a high affinity to $5^{\prime}$-cap structure ${ }^{25,26}$ (Supplementary Fig. 1a, b). According to our experience and previous reports, this is the most effective strategy for mRNA enrichment ${ }^{26}$, as the efficiency of mRNA enrichment and depletion of other unwanted high-abundance RNA species was estimated by quantitative PCR (qPCR) and northern blot analysis for selected transcripts (Supplementary Fig. 1c-e). RNA prepared in such a way isolated from lipopolysaccharide/interleukin 4 (LPS/IL-4)-activated splenic B cells (WT and Tent $5 c$ KO mice) was adapted for Nanopore direct RNA sequencing with the MinION device ${ }^{24}$ (Fig. 1a).

Using ONT sequencing, we obtained in total 2.5 million mappable transcriptome-wide full-length native-strand mRNA reads (Supplementary Table 1), which were used for the analysis of steady-state poly $(\mathrm{A})$ tail lengths in responsive $\mathrm{B}$ cells. The data were reproducible (Supplementary Fig. 1f) while the accuracy of poly(A) length estimations was evaluated with the poly (A) standards, barcoded mRNA transcripts with predefined poly(A) tails ${ }^{27}$, introduced at library preparation step. Distribution of their poly(A) lengths was consistent with the previous reports, with peak values as expected (Supplementary Fig. $1 \mathrm{~g}$ ). We observed no global changes in the mRNA polyadenylation status between WT and TENT5C-deficient cells (Fig. 1b). However, mRNAs encoding Igs had their peak length of the poly(A) tails significantly decreased from 60 in WT to 41 adenosines in KO cells. This was observed for transcripts encoding both heavy and light Ig chains (Fig. 1c, d). The effect was highly specific to Ig transcripts as poly (A) tails of other highly abundant mRNAs, such as ribosomal 


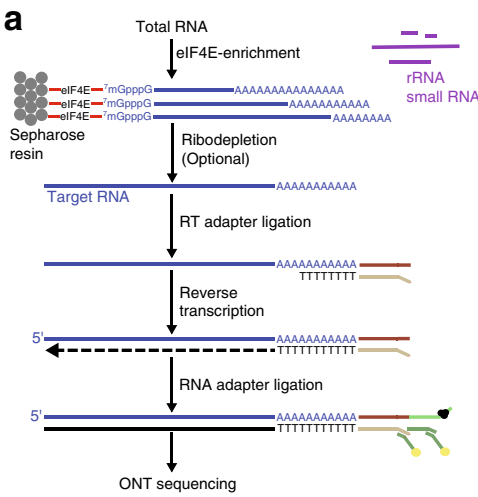

b

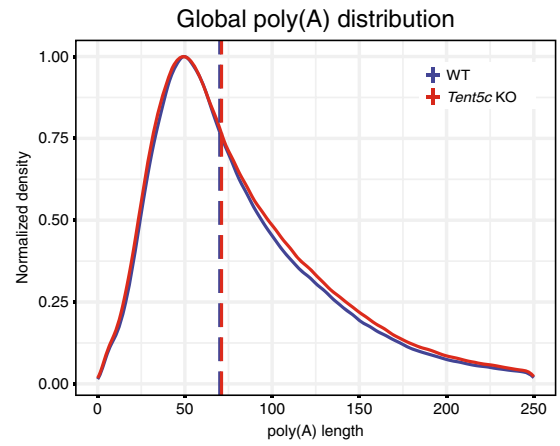

c

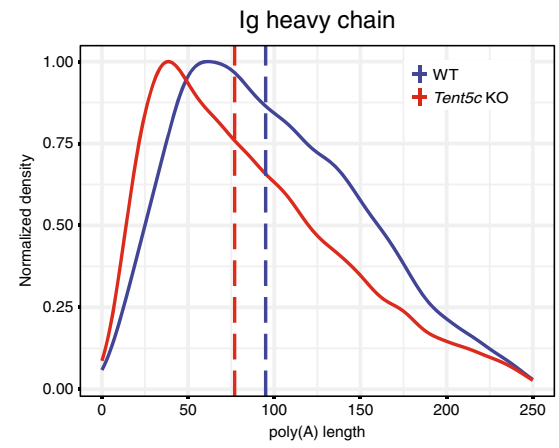

f d

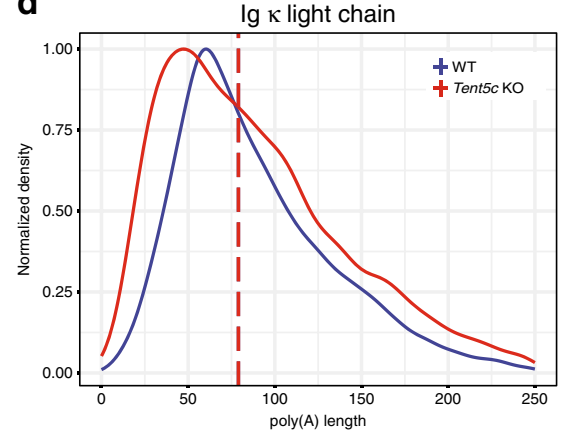

g

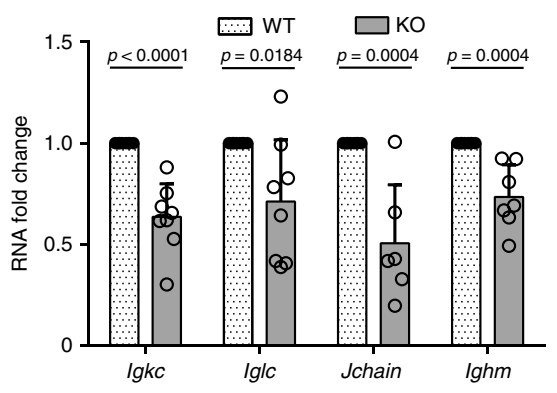

e

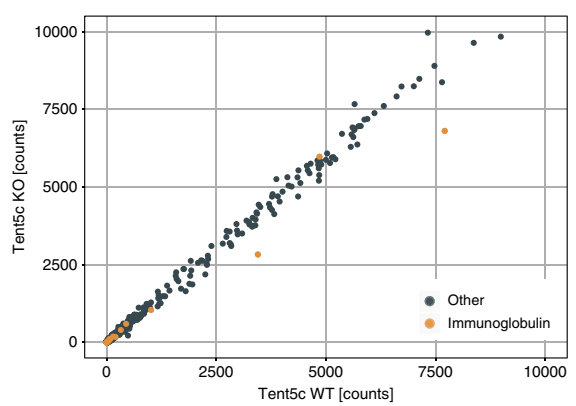

h

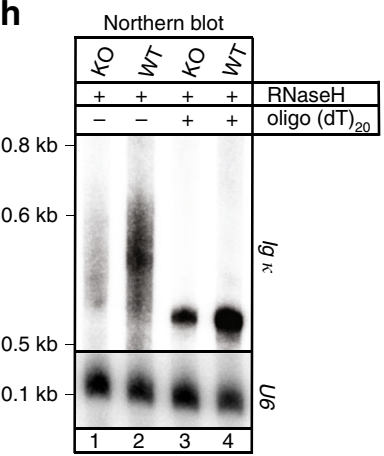

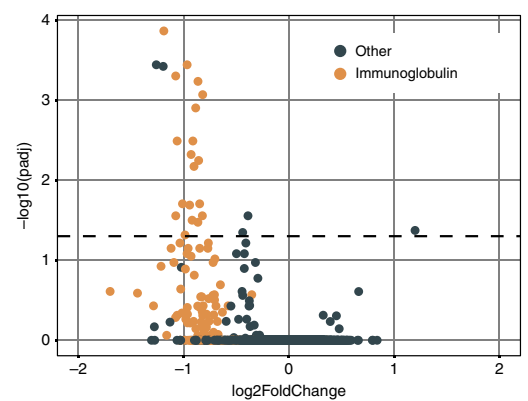

i

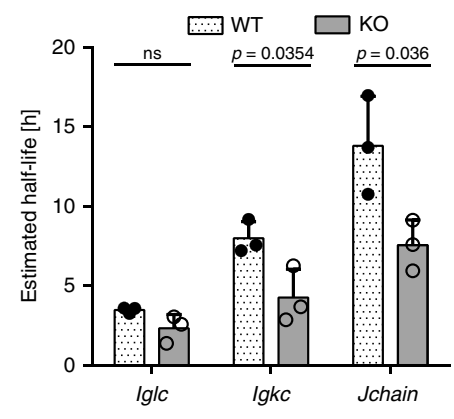

Fig. 1 TENT5C regulates the steady-state level of Ig mRNAs through polyadenylation. a Library preparation workflow for Nanopore direct RNA sequencing. b-d Nanopore-based poly(A) lengths profiling of mRNA isolated from WT and Tent $5 \mathrm{c}$ KO B cells activated for 7 days. Density distribution plots for all transcripts $\mathbf{b}$, Ig heavy $\mathbf{c}$, and Ig light (kappa) chains transcripts $\mathbf{d}$ scaled to a maximum of 1 , are shown. Vertical dashed lines represent median poly (A) lengths for each condition (for $\mathbf{b}$ and $\mathbf{d}$ lines for both conditions are overlapped). e Scatter plot of raw counts for individual transcripts obtained with Nanopore direct RNA sequencing for WT and Tent5c KO. Igs transcripts $(n=39)$ are marked in orange. $\mathbf{f}$ Volcano plot showing the results of DESeq2 differential expression analysis on data from Illumina sequencing of RNA isolated from B cells of WT and Tent5c KO mice activated for 7 days. Igs transcripts $(n=138)$ are marked in orange. Dashed line marks the $P$ value significance threshold $(0.05)$. $g$ RT-qPCR analysis of Igs mRNA expression in WT and Tent5c KO cells. Bars represent mean fold change values \pm SD (Jchain $n=6, \operatorname{lghm} n=7, \operatorname{lgkc}, \operatorname{lglc} n=8$ ). Values are shown as fold changes to WT. h The Ig $\kappa$ mRNA poly(A) tail is reduced in Tent5c KO cells. Northern blot analysis of Ig $\kappa$ mRNA and U6 RNA (loading control) from Tent5c KO and WT B cells activated for 7 days, treated with RNase $\mathrm{H}$ in the presence of oligo(dT) ${ }_{20}$. i RNA half-life calculation with 4-thiouridine labeling method. WT and Tent5c KO B cells activated for 7 days were labeled with 4sU for $1 \mathrm{~h}$. RNA was biotinylated and 4sU-labeled RNA was purified on streptavidin beads. Igs mRNAs half-lives were estimated based on 4sU-labeled RNA enrichment measured by RT-qPCR analysis. Bars represent the mean of calculated half-life values \pm SD ( $n=3)$. P values were calculated using DESeq2 (v.1.22) with standard settings $\mathbf{f}$; two-tailed unpaired Student's $t$-test $\mathbf{g}$, $\mathbf{i}$; not significant (ns); n-biological replicates. Source data: Supplementary Datasets 1 (1b-e) and 2 (1f), Source Data file (1g, i), Supplementary Fig. 8 (1h).

proteins or mitochondrial transcripts were not affected at all (Supplementary Fig. 1h, i). Importantly, poly(A) tails of mitochondrial transcripts were predicted to be $\sim 52$ adenosines (Supplementary Fig. 1i), being in agreement with the existing knowledge ${ }^{28-32}$. Finally, differential expression analysis based on ONT data showed that the abundance of Ig mRNAs was also decreased in Tent5c KO cells (Fig. 1e, Supplementary Dataset 1).

In parallel with direct RNA-seq, we performed standard Illumina RNA sequencing, allowing us to perform a comparative correlation analysis between datasets. Again, Ig mRNAs were the most downregulated ones in Tent5c KO (Fig. 1f, Supplementary Dataset 2), which was additionally confirmed by RT-qPCR (Fig. 1g). To verify RNA-seq data on Ig expression, naive, spleenderived B cells from WT and KO mice were activated with LPS and IL-4, and selected mRNAs were analyzed by northern blot. The Ig $\mathrm{k}$ transcripts are again less abundant and migrate faster on the gel in Tent5C KO compared to those from WT, confirming that they are TENT5C substrates (Fig. 1h, Supplementary Fig. 1j). Next, we confirmed that the observed Ig-encoding mRNA lengthening is indeed caused by mRNA polyadenylation using 
an RNase $\mathrm{H}$ cleavage assay with oligo(dT) ${ }_{20}$ (Fig. 1h). Importantly, Tent $5 c$ is the only one of the four members of the Tent 5 gene family expressed at detectable levels in B cells, and undergoing strong induction during their activation and differentiation as we measured by real-time qPCR (Supplementary Fig. 1k). Interestingly, its expression positively correlates with the upregulation of $P a b p c 1$, suggesting that mRNA polyadenylation contributes to transcriptional reprogramming of the $\mathrm{B}$ cell response (Supplementary Fig. 1k).

Finally, in order to determine whether the Ig mRNAs polyadenylation impacts their stability, we evaluated the halflives of selected transcripts identified in ONT sequencing as TENT5C substrates. Using 4-thiouridine (4sU) labeling of nascent transcripts followed by biotinylation, separation on streptavidin beads, and qPCR-based estimations, a significant decrease in half-life of Ig mRNAs was detected in Tent $5 c$ KO cells (Fig. 1i). Experiments based on transcription inhibition by actinomycin D revealed the same trend (Supplementary Fig. 11). Therefore, we conclude that mRNA polyadenylation by TENT5C leads to Igs mRNA stabilization and enhances their expression.

B cells isolated from Tent5c KO produce fewer antibodies. Next, we analyzed the impact of inefficient transcript polyadenylation on Ig production level using western blot. Tent $5 c \mathrm{KO}$ $\mathrm{B}$ cells grown in vitro produced fewer antibodies than those isolated from WT littermates (both light and heavy chains), while the levels of other secreted proteins: IL-6, as well as ER-associated chaperonin-GPR94, were not changed as much (Fig. 2a). Accordingly, the analysis of media collected from B cell cultures confirmed decreased levels of secreted antibodies by activated TENT5C-deficient B lymphocytes (Fig. 2b). Moreover, flow cytometry revealed that the level of IgG1-positive cells is significantly reduced in TENT5C-deficient B cells after 3 days of activation with IL-4 and LPS in vitro (Fig. 2c).

Next, to get insight into physiological regulation of $\mathrm{Ig}$ production, we assessed the intracellular (cytoplasmic) levels of IgG1 and IgA in a population of CD138-positive cells isolated from the BM, and spleen of WT and Tent $5 c \mathrm{KO}$ mice. The intracellular levels of Igs, in contrast to surface Igs, reflect the secreting ability of these cells. We observed that the percentages of IgG1 and IgA-positive cells are lowered in Tent5c KO mice, which confirms the altered Ig production (Fig. 2d, e). To extend these studies, we did blood serum protein electrophoresis (SPEP) to compare globulin fractions and ELISA tests to assess Ig concentrations in WT and KO mice serum. In agreement with the previous in vitro and in vivo cell analyses, we have found a substantial decrease of gamma globulin fraction (which contains mainly whole antibodies) in $\mathrm{KO}$ mice plasma reflecting alterations in their production and secretion by B cell lineage (Fig. 2f). The decrease in gamma globulins was specific since total serum protein concentrations, as well as albumin, alpha, and beta globulin plasma subfractions, were not reduced. A slight decrease of alpha 2 globulin concentration in Tent $5 c \mathrm{KO}$ serum is most likely a consequence of previously reported by us microcytic anemia $^{21}$ that develops in $\mathrm{KO}$ mice presumably as a result of inhibited globin synthesis, but not due to iron uptake deficiency as its levels were unchanged in the serum (Fig. $2 \mathrm{~g}$ ). In agreement with this, quantification of $\operatorname{IgA}, \operatorname{IgM}, \operatorname{IgG} 1, \operatorname{IgG} 2 \mathrm{a}, \operatorname{IgG} 2 \mathrm{~b}$, and IgG3 Igs in serum by ELISA revealed significantly decreased concentrations in $\mathrm{KO}$ mice compared to WT littermates (Fig. 2h).

Finally, to assess if the lack of TENT5C affects the development of humoral response, we immunized mice against T-celldependent (TD; ovalbumin (OVA)) and T-cell-independent TI (TNP-LPS) antigens. Quantification of specific antibodies by ELISA tests showed clearly that $\mathrm{TI}$, but not $\mathrm{TD}$ response is substantially affected in $\mathrm{KO}$ comparing to WT mice (Fig. 2i, j). This also suggests that polyadenylation by TENT5C plays a more important role in early innate immune response signaling rather than in T-dependent antibody responses.

TENT5C is expressed at late stages of $B$ cell differentiation. Next, we have generated Tent $5 c$-GFP knock-in mice using the CRISPR/Cas9 approach and used flow cytometry to analyze TENT5C expression in B cell lineage further. Similarly to the previously published Tent $5 c-\mathrm{FLAG}^{21}$, the GFP knock-in mouse line did not display any gross phenotype. In vitro-activated $B$ cells isolated from Tent $5 c$-GFP mice revealed a distinct GFP-positive cell population, absent in the non-tagged controls confirming the utility of our mouse model (Fig. 3a). Naive B cells from Tent $5 c$ GFP mice and WT littermates were activated with LPS and IL-4, and subjected to cytometric analysis to measure TENT5C-GFP and CD138 PC markers levels in a time-dependent manner. This analysis revealed that TENT5C is mainly expressed in the population of CD138-positive cells, suggesting the involvement of this enzyme in the last steps of B cell differentiation (Fig. 3b). To confirm this hypothesis, we have systematically examined spleen and BM-residing B cell and PC subpopulations from young adult (12-15 weeks) unimmunized WT and Tent5c-GFP mice using multicolor flow cytometry. The GFP-tag knock-in does not affect the general distribution of B cell and PC populations. However, this approach revealed that the $\mathrm{CD} 138^{\text {high }} \mathrm{B}$ cell subset is also highly GFP positive in both BM (up to 76\%) and spleen (up to 93\%; Fig. 3c). In turn, GFP-positive cells were not detected in B cell subsets at the early stages of differentiation (Supplementary Fig. 2). The detailed gating strategy is presented in Supplementary Figs. 3 and 4. Thus, TENT5C-GFP is mainly expressed in the last stages of B cell differentiation as revealed by detailed PC subpopulation analyses, including dividing plasmablasts (CD19high/ CD45R high), early PCs (CD19high/CD45R low $)$, and mature resting

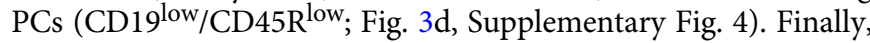
we confirmed those results with immunostaining of spleen sections showing that GFP-fused TENT5C is mainly expressed in CD138-positive cells (Fig. 3e).

TENT5C expression is stimulated by innate signaling. Next, to define whether other stimuli than a combination of LPS and IL-4 lead to TENT5C upregulation, we have tested the main types of B cell activators. Naive B cells isolated from Tent $5 c$-GFP mice and WT littermates as controls were activated with a panel of TLR receptor agonists, mainly pathogen-associated molecular patterns molecules, ligands of CD40 (TD signaling), and B cell receptor (BCR). Subsequent flow cytometry analyses of those cells revealed a significant number of GFP and CD138-positive cells, similar to positive control, as a result of stimulation of selected TLR receptors, including TLR1/2 (Pam3CSK4), TLR2 (HKLM), TLR4 (LPS, Escherichia coli K12), TLR6/2 (FSL1), and TLR9 (ODN1826 (Fig. 4). Stimulation of TLR3 (low and high molecular weight Poly(I:C)), TLR5 (Flagellin Salmonella typhimurium), and TLR8 (ssRNA40/LyoVec) showed a rather limited effect on TENT5CGFP expression.

Subsequent analysis of the PC subpopulations in CD138 high (Q3 for WT; Fig. 4a) and CD138 ${ }^{\text {high }}$ GFPpos (Q2 for TENT5CGFP; Fig. 4b) cell fractions, using CD19 and CD45R markers showed a similar response to the treatment for cells isolated from both mouse lines. In turn, signaling provided by BCR stimulated with polyclonal $\mathrm{F}(\mathrm{ab}) 2$ goat anti-mouse IgM and CD40 receptor with megaCD40L (trimeric variant) had limited effect on TENT5C expression; however, they induced the differentiation of PCs (Fig. 4). 
a

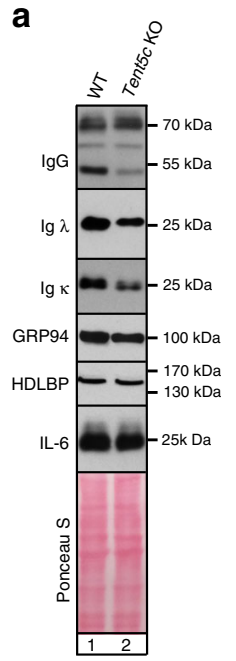

b
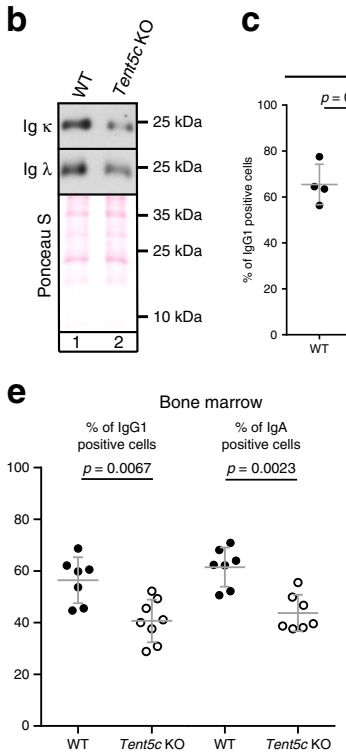

c
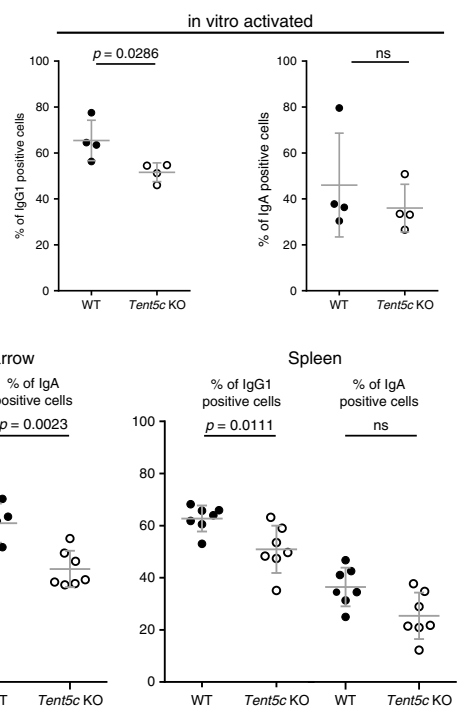

f
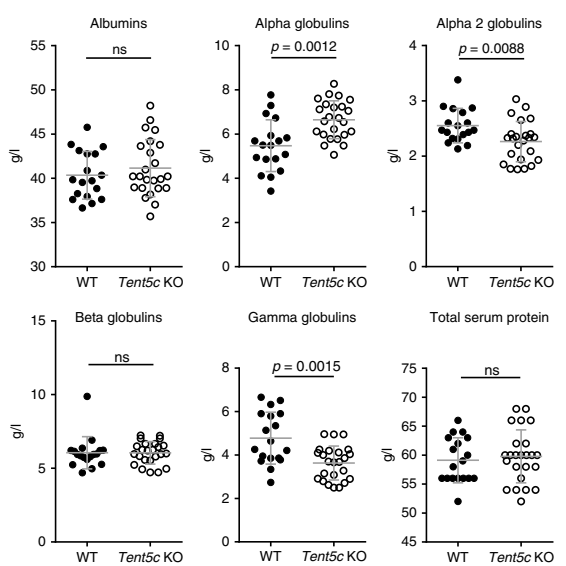

Gamma globulins

Total serum protein
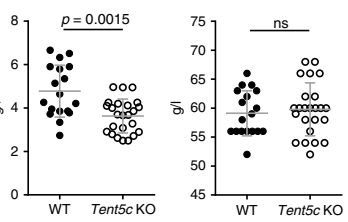

h
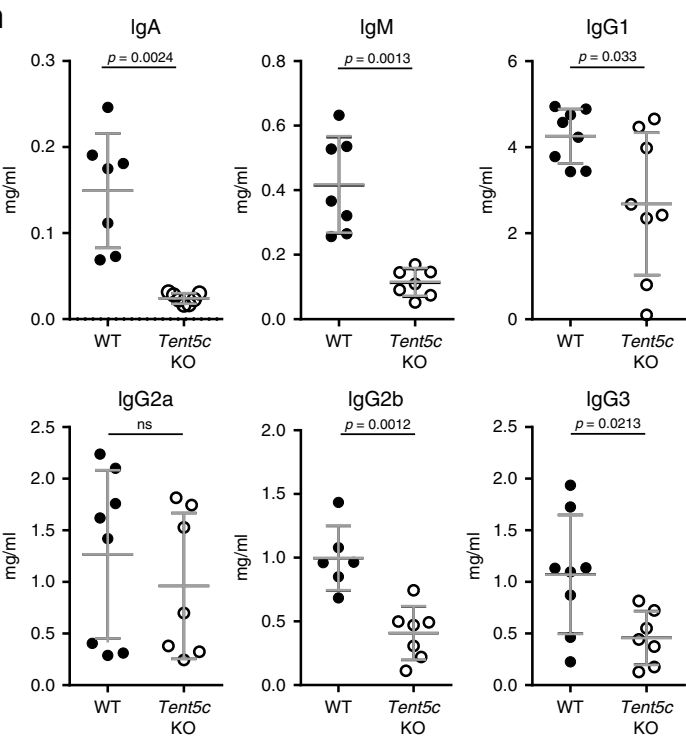

To assess whether antibody production is also impaired in Tent $5 \mathrm{c}$ KO B cells activated via innate signaling pathways, we activated B cells from WT and KO with TLR agonists with the highest effect on TENT5C expression (TLR1/2, TLR4, TLR6/2, and TLR9 agonists) in a time course, then collected cells and medium for western blot g Serum iron level

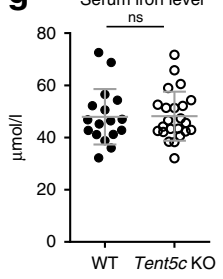

WT Tent5c KO

i

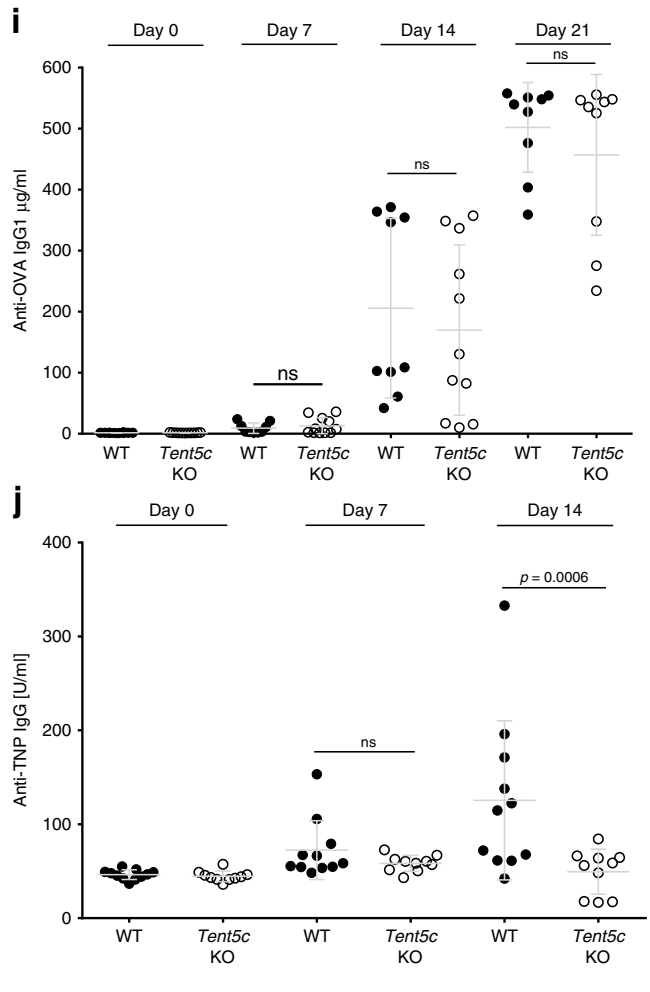

d Bone marrow
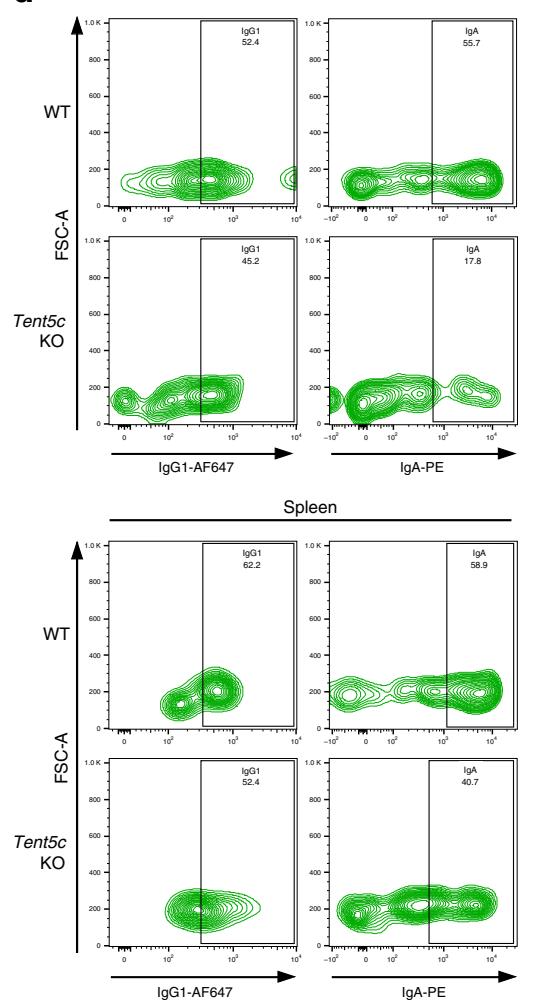

analysis at days 3 and 5. Indeed, we observed decreased secretion of both heavy IgG and light chains in KO, while $\alpha$-tubulin and GRP94 levels were unaffected (Supplementary Fig. 5).

All this together links B cell-intrinsic innate signaling via selected TLRs with the regulation of adaptive humoral immunity 
Fig. 2 Tent5c KO produces less antibodies and has impaired immune response. $\mathbf{a}, \mathbf{b}$ Western blot analysis of extracellular lgG heavy and light ( $\kappa$ and $\lambda$ ) chains, GRP94, HDLBP, and IL- 6 a or secreted $\kappa$ and $\lambda$ light chains $\mathbf{b}$ from WT and Tent5c KO activated B cells. Ponceau S staining was used as a loading control. c Percentage of IgG1 and IgA-positive cells in WT and Tent5c KO B cells activated in vitro for 3 days $(n=4)$. $\mathbf{d}$ Intracellular lg isotypes levels in mature resting PCs. Cell populations were analyzed based on CD138, CD19, CD45R, IgG1, and IgA staining. Pseudo-color dot blots are showing FSC-A vs IgG1-AF647 or IgA-PE fluorescence. Gating strategy in Supplementary Fig. 4. e Percentage of mature resting PC-positive cells for intracellular lgG1 or lgA isotypes ( $n=7$ or $n=8$ for \% of lgG1-positive cells in KO BM). f Blood serum albumins, alpha 1 globulins, alpha 2 globulins, beta globulins, gamma globulins, and total protein levels in Tent5c KO and WT by SPEP (WT $n=18, \mathrm{KO} n=24)$. $\mathbf{g}$ Iron levels in blood serum of Tent5c KO and control animals (WT $n=17, \mathrm{KO} n=23$ ). h Measurements of IgA, IgM, IgG1, IgG2a, IgG2b, IgG3 in WT and Tent5c KO mice serum $(n=6-8)$. i TENT5C deficiency does not impair the immune response against a T-cell-dependent antigen. OVA-specific serum IgG1 antibodies concentrations were measured with ELISA on days 7, 14, and 21 postimmunization with OVA-CFA. Mean anti-OVA IgG1 concentrations $(\mu \mathrm{g} / \mathrm{ml}) \pm \mathrm{SE}(\mathrm{WT} n=9, \mathrm{KO} n=10)$. $\mathbf{j}$ TENT5C deficiency impairs the immune response against a type 1 T-cell-independent antigen. TNP-specific serum IgG concentrations were measured with ELISA on days 7 and 14 postimmunization with TNP-LPS. The graph shows mean anti-TNP IgG concentrations $(\mathrm{U} / \mathrm{ml}) \pm \mathrm{SE}(\mathrm{WT} n=11, \mathrm{KO} n=10)$. P values were calculated using two-tailed Mann-Whitney $U$ test $\mathbf{c}$, e; two-tailed unpaired Student's $t$-test with Welch's correction $\mathbf{f}-\mathbf{h}$; one-way ANOVA with Tukey's multiple comparison test $\mathbf{i}$, j; not significant (ns); data shown as mean values $\pm S D$, unless otherwise indicated; $n$-biological replicates. Source data: Supplementary Fig. $8(2 a, b)$ and Source Data file (2c, e-j).

modulated by ncPAP TENT5C and reveals this enzyme as an important modulator of $\mathrm{B}$ cell response.

Tent $5 c \mathrm{KO}$ leads to accelerated B cell differentiation. Tent $5 c \mathrm{KO}$ leads to an increased B cell proliferation, suggesting that TENT5C may control the process of their differentiation into $\mathrm{PCs}^{21}$. Since the terminal differentiation of $\mathrm{B}$ cells takes place in the secondary lymphoid organs, we carried out extended phenotyping of B cells in the spleen, as well as BM. First, we observed that spleens in KO mice are particularly $\sim 20 \%$ enlarged compared to those isolated from WT (Fig. 5a), while there is no difference in overall animal mass (Fig. 5b). As this observation strongly suggested enhanced proliferation rates, we have systematically examined B cell subpopulations from spleens and BM of conventionally cohoused adult unimmunized littermates (12-16 weeks) using multicolor flow cytometry.

Interestingly, we observed that the number of CD138 high cells in the spleen and BM was significantly increased in Tent5c KO mice (Fig. 5c, d). Next, we carried out the quantitative determination of CD138 high PC subpopulations in WT and KO mice. This has revealed mature resting PCs as the only cells whose number is increased in Tent5c KO mice spleen and $\mathrm{BM}$, while the numbers of dividing plasmablasts and early PCs were slightly decreased or not changed in $\mathrm{KO}$ (Fig. 5e). Interestingly, other $\mathrm{B}$ cell subpopulations in the BM (pre-proB, pro- $\mathrm{B}$, pre- $\mathrm{B}$, immature, early/late mature, and transitional $B$ ) and in the spleen (transitional (T1/T2/T3), marginal zone (MZP and MZ), follicular (I and II)) were not affected by Tent5c KO (Supplementary Fig. 6). All these observations clearly suggest that the lack of TENT5C leads to the enhanced $\mathrm{B}$ cell proliferation and differentiation in vivo, and confirms previous in vitro findings.

Next, we asked whether Tent5c KO influences the secondary antibody repertoire generated by class switch recombination (CSR), which replaces IgM with other isotypes during B cell differentiation into PCs, and whether it differs in the KO compared to the WT. The changes in the class profile of presented antibodies may indicate a disturbance in the CSR process. We observed that $\mathrm{CD} 138^{\text {high }} \mathrm{B}$ cell subsets in Tent5c KO lose IgA expression much faster as compared with WT, which confirms their faster proliferation and accelerated selection of IgG1-expressing polyclonal PCs, indicating alerted CSR in the KO mutant (Fig. 6a, b). The general concentration of Igs is lowered in $\mathrm{KO}$ cells as a result of a diminished expression level and they accumulate membrane-bound IgG1 (Fig. 6c, d). This is in agreement with the results, we obtained for in vitro cultured $B$ cells (Fig. 2a, b).

Tent5c is essential for ER expansion in activated B cells. The transition of B cells into Ig-secreting PCs requires a significant expansion of secretory organelles, given that ER-specific chaperones and folding enzymes facilitate the posttranslational structural maturation of Ig. Since TENT5C modifies transcripts encoding Ig in responding B cells, it may have a possible ERrelated function. To examine the link between TENT5C activity and ER functionality, we performed a fractionation of activated $\mathrm{B}$ cells isolated from Tent5c-GFP mice through discontinuous sucrose gradients followed by western blot analysis ${ }^{33}$. This approach confirmed that TENT5C-GFP mainly localized in the cytosol. However, there is a minor fraction of the membranebound enzyme that suggests its involvement in the mRNA polyadenylation directly on ER (Fig. 7a). It was supported by a partial intracellular co-localization of endogenous TENT5C-GFP protein with the ER selectively stained by tracker dye in ex vivoactivated B cells (Fig. 7b). Finally, co-immunoprecipitation (CoIP) experiments using high-affinity anti-GFP nanobodies followed by high-resolution mass spectrometry (MS) revealed that TENT5C-GFP interacts with ribosomal proteins, suggesting that TENT5C which may directly polyadenylate Ig mRNAs at the RER (Supplementary Dataset 3).

As B lymphocyte maturation requires a significant increase in ER volume and Tent5c KO leads to the increased rate of the differentiation process, we compared its size and expansion dynamics during the activation of WT and $\mathrm{KO} \mathrm{B}$ cells, using specific ER-tracker dye labeling followed by flow cytometry analyses. The results of these experiments showed that a lack of TENT5C impairs the capacity of the secretory pathway through the reduction of ER volume (naive and mature resting PC; Fig. 7c, d). Moreover, the dynamic of the ER expansion after activation is much slower in the TENT5C-deficient cells despite their accelerated differentiation into plasmocytes (Fig. 7e). Reduced ER in Tent5c KO cells is consistent with decreased levels of both Ig-encoding transcripts and the main chaperone Hspa5 (BIP), necessary for the correct functioning of the ER (Supplementary Dataset 2). Thus, our findings, together with the fact that the overall rate of antibody production in $\mathrm{KO}$ cells is reduced, strongly suggests that B cells isolated from Tent5c KO may have reduced ER stress levels. In order to analyze the ER stress response, we treated activated WT and KO B cells with the standard ER stressinducing agent tunicamycin (Tu), and then analyzed UPR markers with qPCR and western blots. Interestingly, the induction of ER stress enhances Tent5c expression (Fig. 7f). Accordingly, the KO cell response for $\mathrm{Tu}$ treatment was significantly diminished as shown by Xbp1 mRNA splicing and expression of selected markers Ire1, Perk, Gro94, Chop, and Ero1-LB, showing a general downregulation of UPR (Fig. 7g-i). In contrast, the initial ER stress level is enhanced in the mutant compared to WT, which probably reflects faster differentiation to PCs.

Concluding, TENT5C dysfunction leads to a reduced ER volume and capacity of the ER stress response, as a probable consequence of a decreased load of Ig. 
a

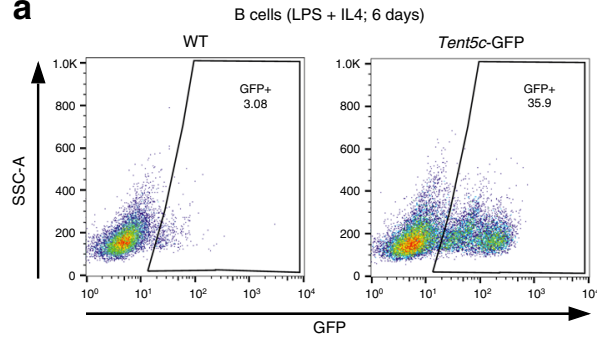

C
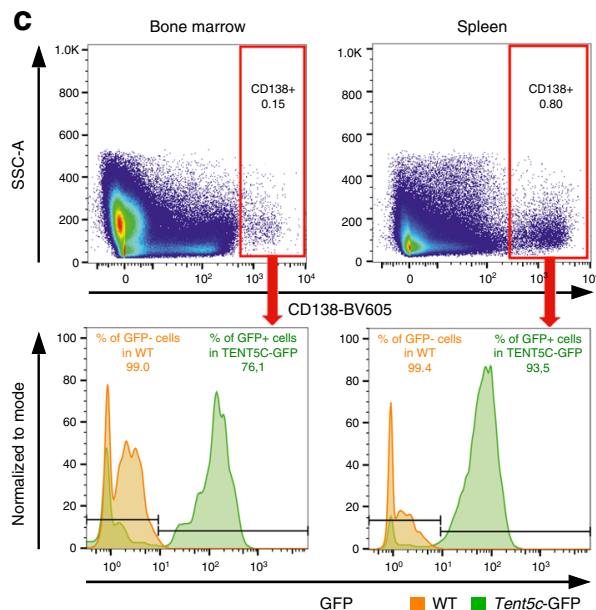

d

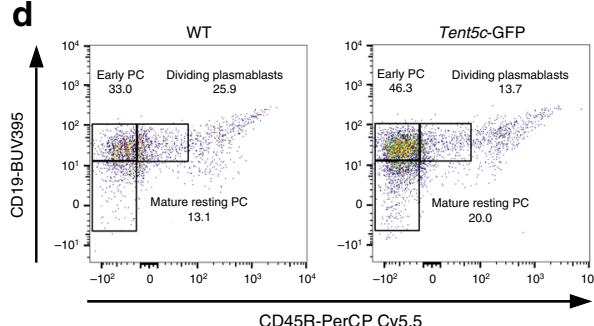

GFP intensity in subpopulations

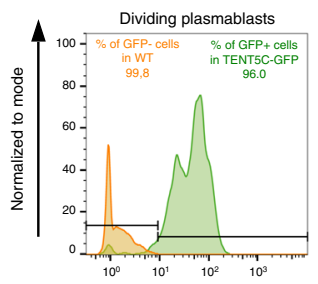

b
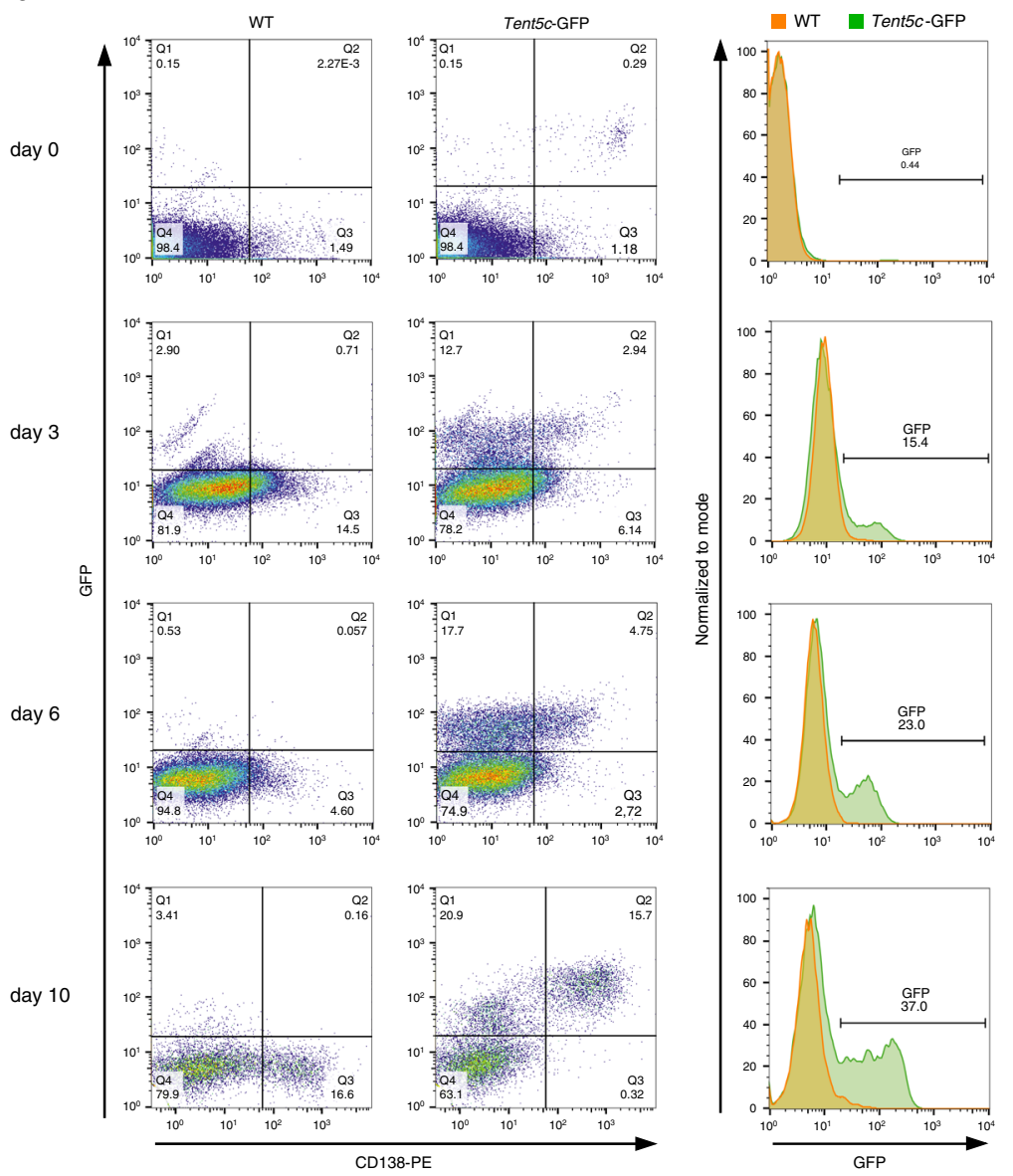

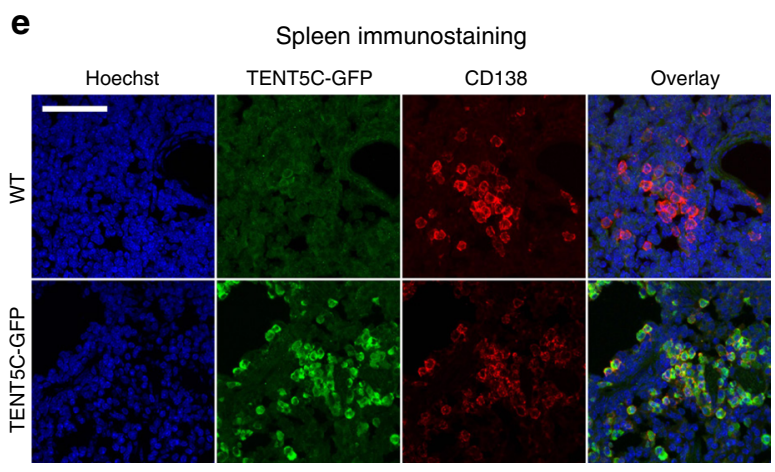

Fig. 3 Expression of TENT5C is limited to the last stages of $\mathbf{B}$ cell lineage differentiation. $\mathbf{a}, \mathbf{b}$ Flow cytometry analysis of TENT5C-GFP expression in a subpopulation of CD138 $8^{\text {high }}$ cells activated in vitro with LPS and IL-4 for 6 days $\mathbf{a}$ or up to 10 days $\mathbf{b}$ presented as pseudo-color dot blot showing SSC-A vs GFP fluorescence or GFP vs CD138-PE fluorescence $\mathbf{a}$ and/or histograms of GFP-fluorescence intensity $\mathbf{b}$. Orange color refers to WT, green is related to Tent5c-GFP. A detailed gating strategy is presented in Supplementary Fig. 4. c, d Flow cytometry analysis of TENT5C-GFP expression in splenocytes and BM $\mathbf{c}$ and different splenic PC subpopulations d: dividing plasmablasts, early PC, mature resting PC. Color code as above. Pseudo-color dot blots are showing SSC-A vs CD138-BV605 fluorescence or CD19-BUV395 vs CD45R-PerCP Cy5.5 fluorescence. See also Supplementary Figs. 2 and 4. e Immunohistochemical staining for PC marker CD138, and GFP in spleens of wild-type and Tent5c-GFP knock-in mice. Scale bar denotes $50 \mu \mathrm{m}$.

Tent5c catalytic mutant mice reproduce KO phenotypes. Since our attempts to show direct interaction of TENT5C with mRNA substrates were unsuccessful, we wanted to see whether the observed phenotypes are directly dependent on the TENT5C activity. To this end, knock-in mice bearing TENT5C D90N and D92N mutations, which, as we have previously shown, inactivate the enzyme $e^{21}$ have been constructed (herein described as Tent $5 c$
Cat). Firstly, we have analyzed RNA isolated from activated B cells from Cat and WT littermates (Fig. 8a, Supplementary Fig. 1j), and we found Igs mRNA poly(A) tail shortening similar to that observed in cells isolated from KO mice (Fig. 1h). Subsequent western blot analysis of activated B cells, as well as the media from in vitro cultures, showed a specific reduction in the levels of Igs (Fig. 8b, c) and lowered percentages of cells positive for 
a

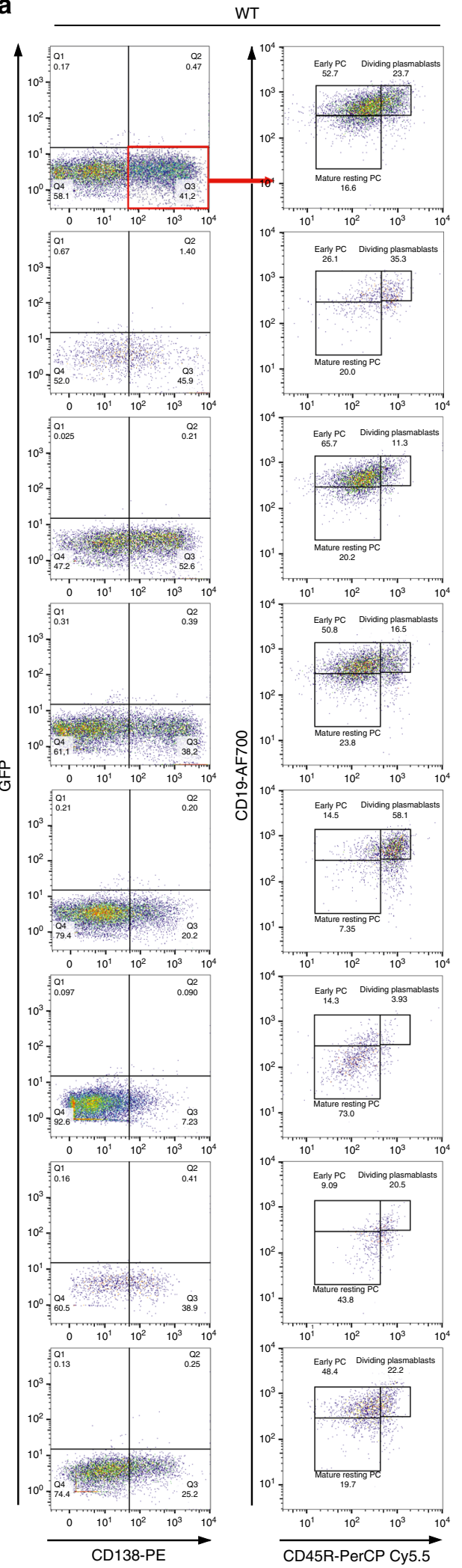

b

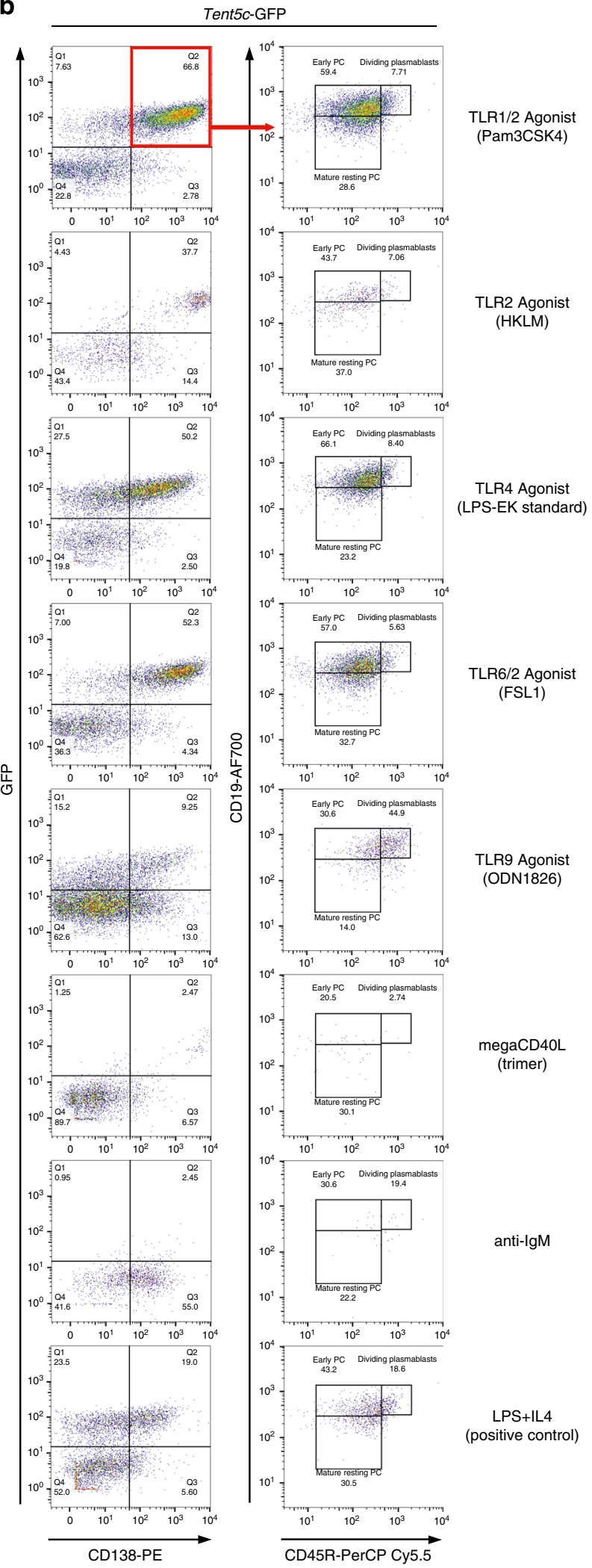

Fig. 4 TENT5C is specifically upregulated by specific TLR. $\mathbf{a}$, $\mathbf{b}$ Analysis of the $B$ cells activation process, measured by the evaluation of co-expression of

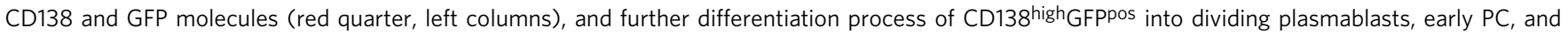
mature resting PC (right column). B cells isolated from WT $\mathbf{a}$ and Tent5c-GFP $\mathbf{b}$ mice, were treated with different activators (indicated on the right part of the plot) for 4 days: TLR1/2 agonist (Pam3CSK4), TLR2 agonist (HKLM), TLR4 agonist (LPS-EK standard), TLR6/2 agonist (FSL1), TLR9 agonist (ODN1826), megaCD4OL (trimer), anti-lgM, and LPS/IL-4 as a positive control. Flow cytometry analysis was based on the live/dead, CD138, CD45R, and CD19 staining and additionally GFP. Pseudo-color dot blots are showing GFP vs CD138-PE fluorescence or CD19-AF700 vs CD45R-PerCP Cy5.5 fluorescence. See also Supplementary Fig. 4. 
a

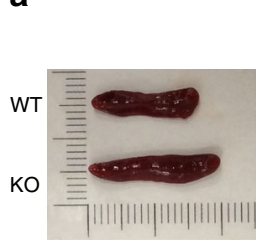

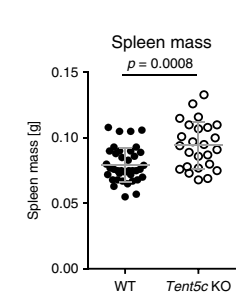

e
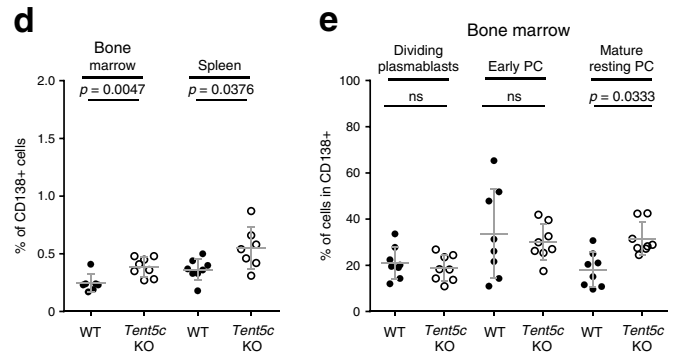

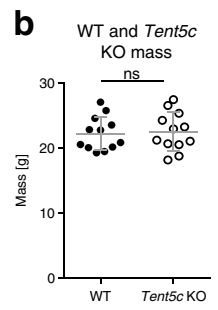

C

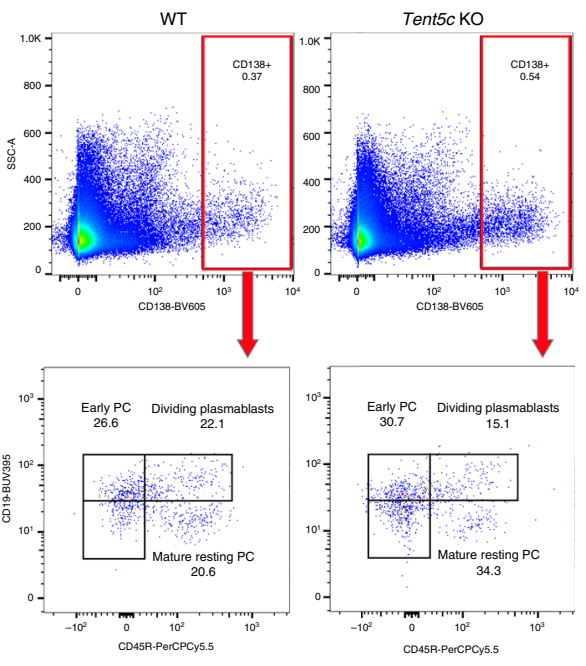

Fig. 5 TENT5C negatively regulates B cell lineage differentiation into PCs. a Comparison of spleen mass in WT and Tent5c KO mice (right panel; WT $n=$ $38, \mathrm{KO} n=25$ ). Pictures (left panel) show the representative difference in the spleen size between WT and Tent5c KO. b Comparison of body mass in WT and Tent5c KO mice $(n=12)$. c Flow cytometry quantitative analysis of CD138positive cells (upper pseudo-color dot blots) and particular CD138high subsets: dividing plasmablasts, early PC, and mature resting PC (lower pseudo-color dot blots) in WT and Tent5c KO. PC populations were analyzed based on CD138, CD19, CD45R, IgM, IgG1, and IgA staining. Pseudo-color dot blots are showing SSC-A vs CD138-BV605 fluorescence or CD19-BUV395 vs CD45RPerCP Cy5.5 fluorescence. The gating strategy is presented in Supplementary Fig. 4. d Percentages of CD138high cells in WT and Tent5c KO in both BM and spleen. (BM: WT $n=7, \mathrm{KO} n=8$, spleen: WT $n=8, \mathrm{KO} n=7$ ). See Supplementary Fig. 6 for other cell subpopulations. e Comparison of CD138high subpopulations (selected as shown in c): dividing plasmablasts, early PC, mature resting PC in WT, and Tent5c KO in both BM and spleen ( $n=8$ ). $P$ values were calculated using two-tailed unpaired Student's $t$-test with Welch's correction $\mathbf{a}$, b, two-tailed Mann-Whitney $U$ test $\mathbf{d}$, and two-way ANOVA with post hoc Bonferroni test e; not significant (ns); data are presented as mean values \pm SD; $n-$ biological replicates. Source: Supplementary Fig. 8 (5a left) and and Source Data file (5a right, 5b, d, e).

intracellular IgG1 in a $\mathrm{CD} 138^{+}$population (Fig. 8d, e) although, the expression of surface IgG1 isoform is enhanced (Fig. 8d, e). In agreement with all these results, analysis of serum proteinograms revealed decreased gamma globulins fraction (Fig. 8f), while other fractions do not differ much (Supplementary Fig. 7a).

At the organismal level, loss of TENT5C catalytic activity leads to the increased spleen size (Fig. 8g) and elevated overall CD138 ${ }^{+}$ cell numbers in BM and spleen (Fig. 8h). Detailed phenotyping of $\mathrm{CD}_{138^{+}}$cells subpopulation from BM and spleen confirmed faster proliferation rate, resulting in an increased number of mature resting PC and decreased the number of cells at earlier steps of differentiation (dividing plasmablasts and early PC) in both BM (Fig. 8i) and spleen (Fig. 8j). Importantly, the early stages of B cell differentiation are not affected in Tent $5 c$ Cat mice (Supplementary Fig. $7 b, c)$. In agreement with this naive B cells isolated from WT and Tent5c Cat activated in vitro with LPS and IL-4 accelerate differentiation into mature PC (Supplementary Fig. 7d).

Finally, similarly to the results obtained with cells isolated from $\mathrm{KO}$, the dynamics of the ER expansion after activation is much slower in the Tent5c Cat cells (Fig. 8k) despite their accelerated differentiation into plasmocytes. All these results prove that described above Ig-related phenotypes in TENT5C-deficient mice are a direct effect of mRNA polyadenylation impairment rather than the absence of TENT5C protein.

\section{Discussion}

B cell development in mice and humans has been extensively studied, revealing complex physiological changes, driven by different signaling pathways, which influence the genome (somatic hypermutation, CSR), transcriptome (through the coordinated action of transcription factors), and proteome (ER reorganization, posttranscriptional gene expression regulation) in differentiating cells. In this study, we provide evidence for cytoplasmic polyadenylation, driven by TENT5C, being the previously undescribed mechanism involved in the regulation of Ig expression, which dysfunction leads to aberrant B cell differentiation. Our data indicate that the role of cytoplasmic polyadenylation is broader than previously anticipated and provides a new layer to the regulation of Ig expression.

Recently, we presented the first experimental data for a new family of non-canonical cytoplasmic poly(A) polymerases TENT5 (formerly FAM46) ${ }^{34}$. One of the members, TENT5C, was shown to be a specific growth suppressor in MM cells ${ }^{21,22}$ and is the only TENT5 family member expressed at significant levels in B lymphocytes. In this work, using direct RNA sequencing by ONT, we identified Ig mRNAs as TENT5C specific targets in activated B cells. This experimental strategy offers high-quality, full-length mRNA sequences, including UTRs and poly(A) tails giving deeper insights into transcriptome shaping, comparing to classical RNAseq experiments ${ }^{32}$. It is characterized by a relative technical simplicity, and in contrast to other RNA-seq methods, no PCR biases are introduced into libraries as in case of other currently used RNA 3'-end research techniques, such as Nascent RNAend-Seq, TAIL-seq, PAL-seq, TED-seq, PAC-Seq, EnD-seq, FLAM-seq, or most recently PAIso-seq ${ }^{31,35-41}$. Importantly, despite the recent dynamic expansion of RNA 3'-terminome research, little was known how cytoplasmic ncPAP enzymes contribute to gene expression programs since such techniques were never applied for KOs of individual enzymes in physiological conditions. Cytoplasmic adenylation was mostly studied in the context of gametogenesis or in other instances, in which transcription is arrested or spatially and temporarily separated. To our knowledge, this is the first report showing an in-depth insight of poly(A) tails dynamics and enzyme specifically controlling their length under native physiological conditions in responding $\mathrm{B}$ lymphocytes. Importantly, a shortening of Ig mRNAs poly(A) tail by $\sim 30 \%$ 

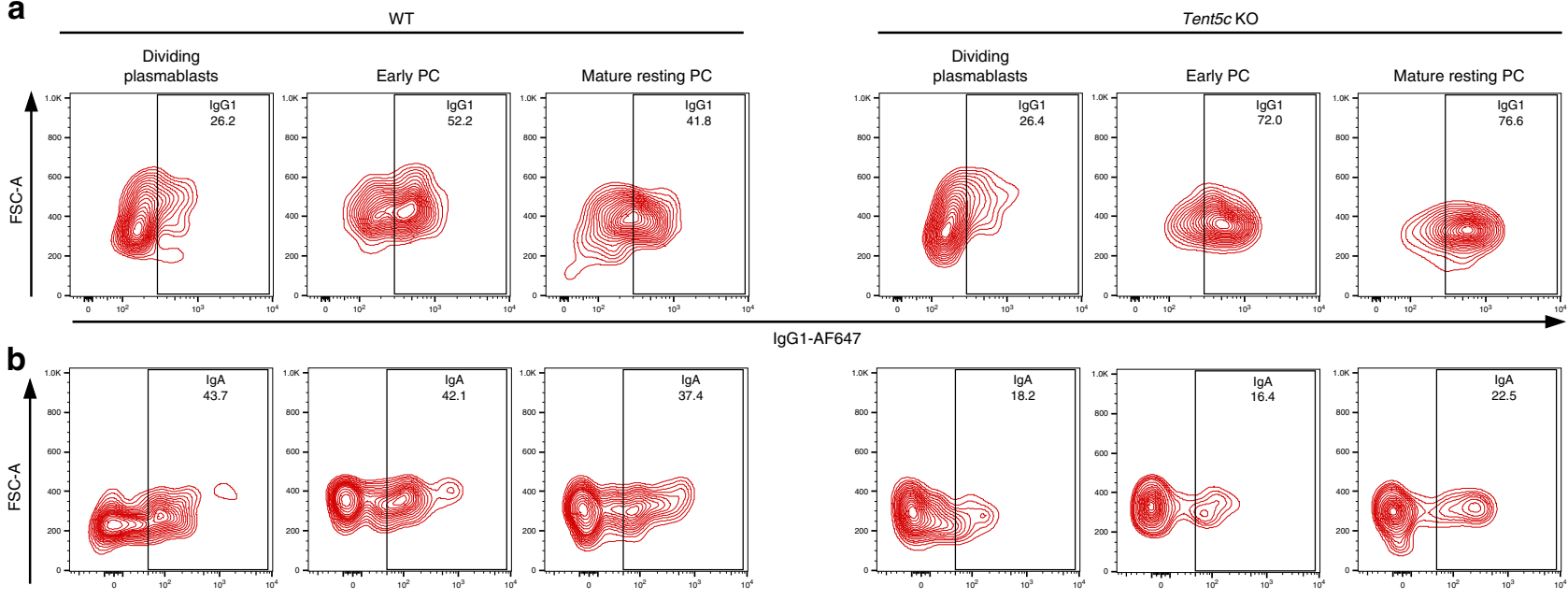

IgG1-AF647

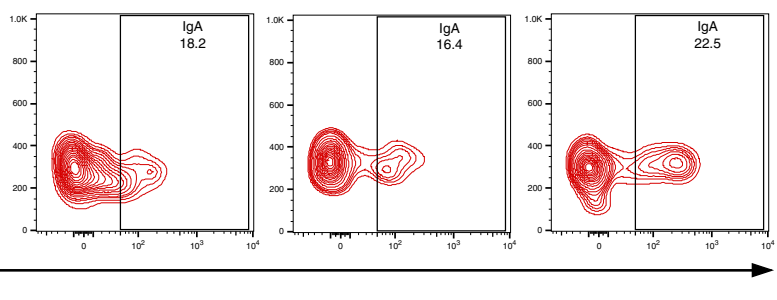

C

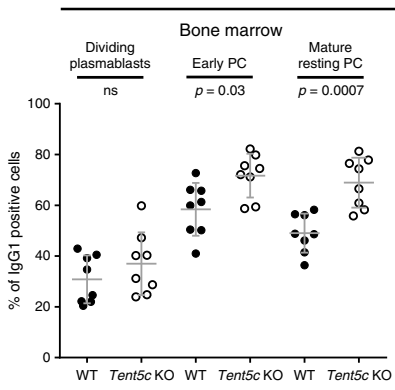

$\lg \mathrm{I} 1$

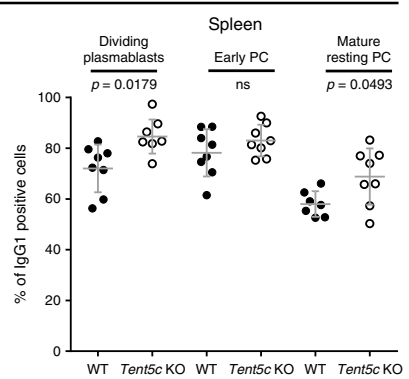

d

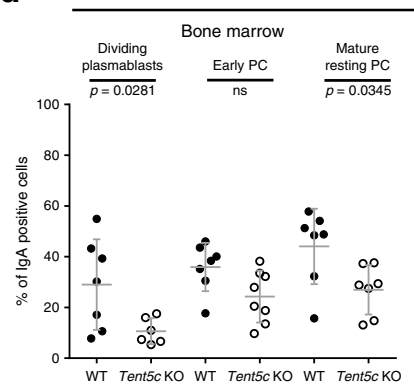

$\lg A$

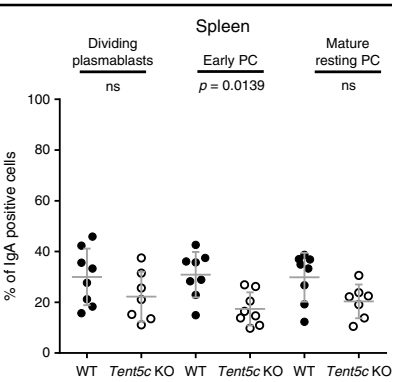

Fig. 6 Tent5c KO plasmocytes are characterized by the abnormalities in the CSR. a, b Flow cytometry analysis of surface IgG1 a, and IgA b, in dividing plasmablasts, early PC, and mature resting PCs isolated from BM or spleen (representative contour blots are shown). PC populations were analyzed based on CD138, CD19, CD45R, IgG1, and IgA staining. Pseudo-color dot blots are showing FSC-A vs IgG1-AF647 fluorescence or FSC-A vs IgA-PE fluorescence. See the gating strategy in Supplementary Fig. 4. c, d Percentage of cells positive for surface IgG1 c, or IgA d, Igs in dividing plasmablasts, early PC, and mature resting PCs isolated from BM or spleen. Data are presented as mean values \pm SD $(n=7-8$, biological replicates). $P$ values were calculated by twoway ANOVA with post hoc Bonferroni test; not significant (ns). Source data: Source Data file (6c, d).

causes a decrease in the half-life of these transcripts by several times and is sufficient for significant reduction of Ig levels in the mice leading to a deficient response to immunization with TI antigen. This proves that cytoplasmic polyadenylation is not restricted to deadenylated maternal mRNAs, as in the case of gametogenesis. However, the mechanism of the substrate specificity and regulation of TENT5C-mediated Ig polyadenylation remains to be established.

Tent $5 c$ was reported as one of the genetic signatures in ASC and a potential regulator of $B$ cell differentiation, and is one of the top 50 upregulated genes in the spleen and BM PCs (ref. ${ }^{42}$ ). Our studies confirm a strong correlation of TENT5C expression with $\mathrm{B}$ cell proliferation and differentiation into PCs. Moreover, it is positively correlated with the upregulation of $\mathrm{PABPC1}$ previously identified as TENT5C interactor in $\mathrm{MM}$ cells ${ }^{21}$. Innate signaling from both surface (TLR1, 2, 4, and 6) and intracellular (TLR9) TLRs strongly upregulate TENT5C levels, thus promote the B cell lineage differentiation and enhance immune response; however, detailed dissection of TLR downstream signaling pathways require further investigation ${ }^{43}$. Interestingly, mice devoid of MyD88 (myeloid differentiation primary response gene 88) gene, which is one of the key elements of TLR signaling, reveal similar phenotypes to TENT5C deletion including: decreased steady-state levels of total serum Igs, decreased antigen-specific IgM and IgG1 antibody responses, and abolished IgG2 antibody response in immunized mice ${ }^{44}$. This strongly suggests that TENT5C is one of the TLR signaling effectors in B cells. In agreement, TENT5C upregulation by specific $\mathrm{B}$ cell innate signaling is underlined by the fact that it is not affected by the stimulation of BCR and CD40 receptor, and also that a decrease in humoral response was only observed in mice immunized with T-cell-independent antigens.

The transition of naive B cells into ASC requires significant ER membrane expansion, given that the structural maturation of Igs is facilitated by ER-residing chaperones and folding machinery ${ }^{1,45-47}$. The increase in the volume of secretory organelles occurs through the generation of ER sheets and requires UPR signaling ${ }^{48}$. It has been shown that XBP1 and BLIMP1 transcription factors are required for PC development and they link B cell physiology with the UPR response ${ }^{49-51}$. Accordingly, the analysis of ASC signature genes identified $30 \%$ of the transcriptome as related to the UPR (ref. ${ }^{42}$ ). Thus, the downregulation of Ig expression in Tent $5 c \mathrm{KO}$ has to impair the UPR, which plays a pivotal role in the differentiation of ASC. In agreement with this, basic ER stress in naive B cells from TENT5C-deficient mice is enhanced, which reflects their faster proliferation and differentiation into $\mathrm{PC}$, while ER expansion dynamics is reduced. This also shows that cytoplasmic adenylation by TENT5C, being the posttranscriptional regulator of Ig expression, may have profound effects on different aspects of $\mathrm{B}$ cell physiology. Although TENT5C activity is predominantly cytoplasmic, it should be marked that further studies are required to exclude its effect on nuclear mRNA tailing. 
a

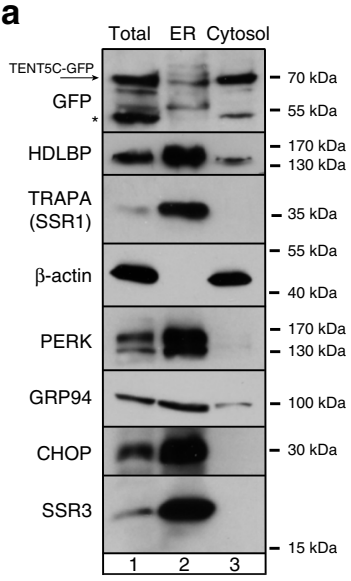

d

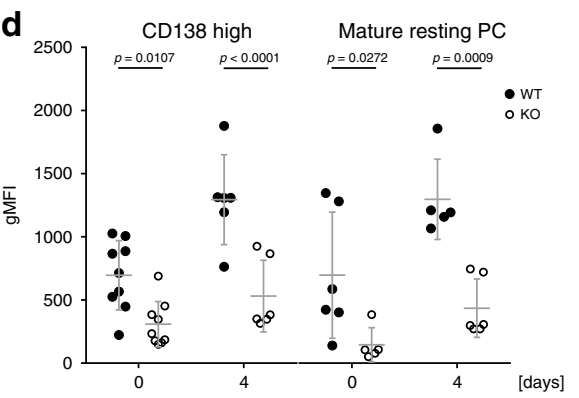

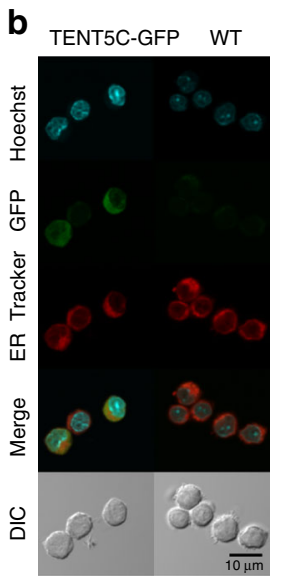
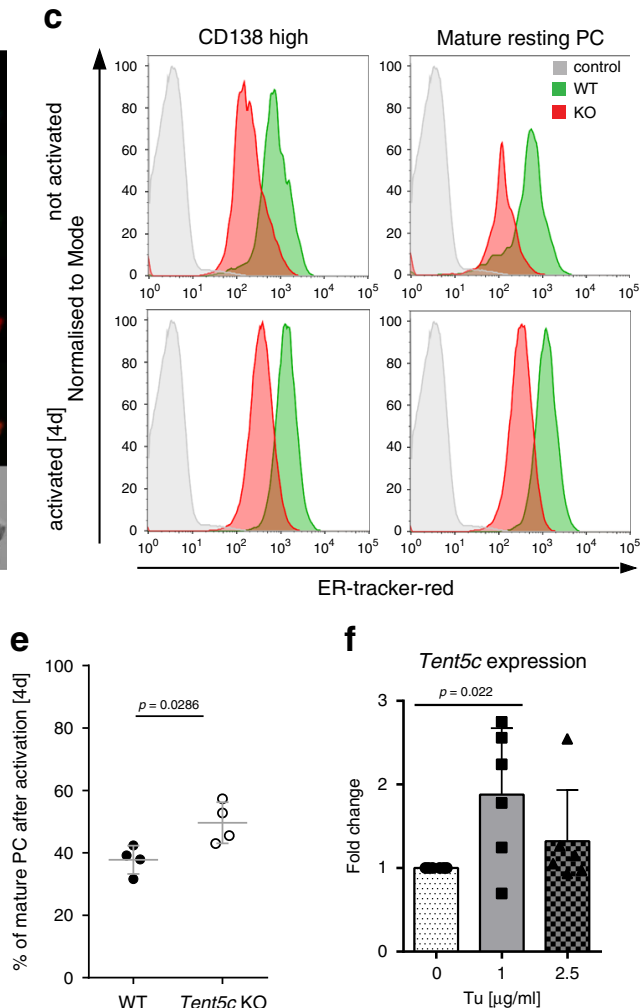

f

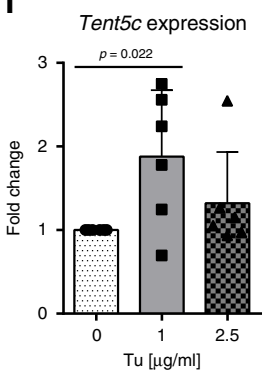

g
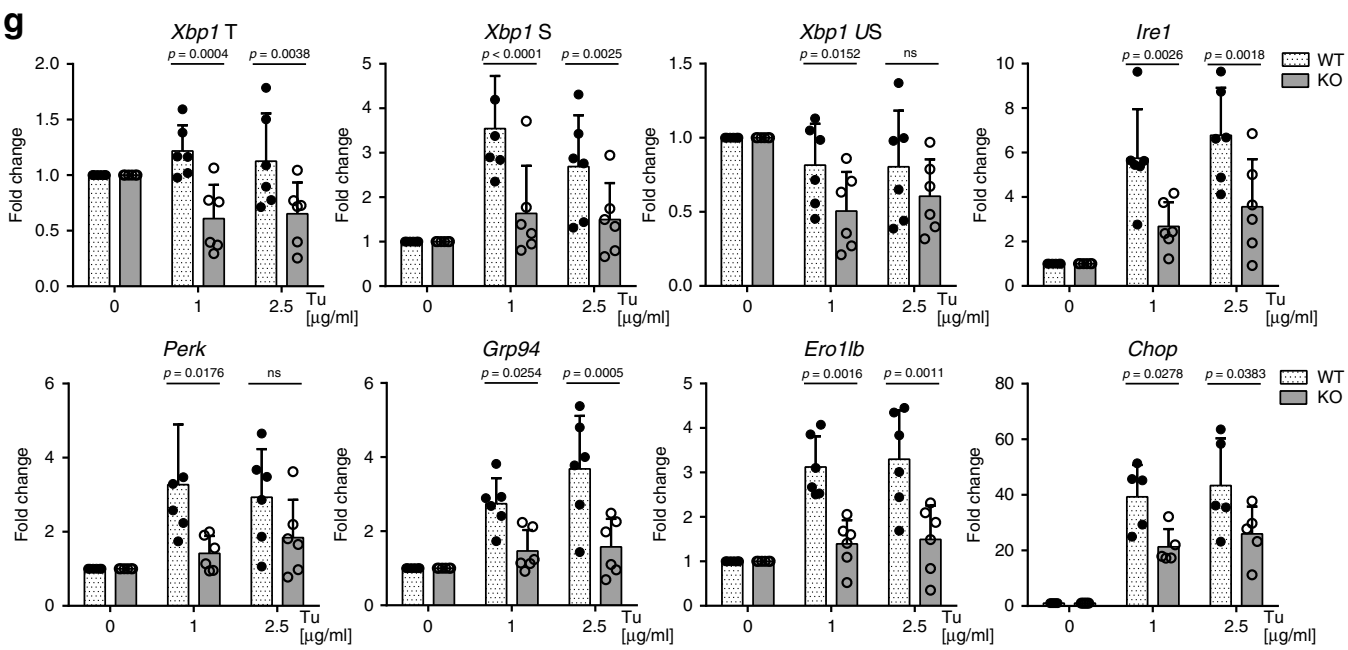

Chop
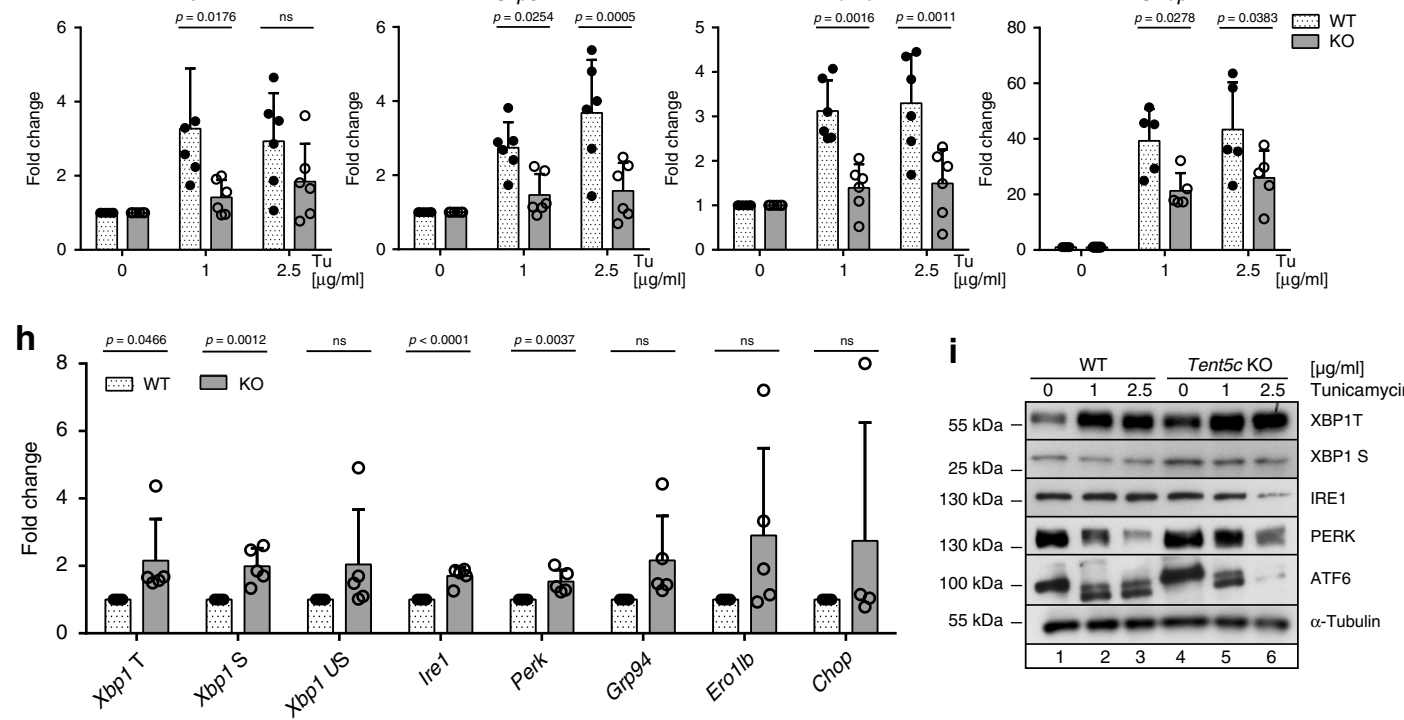

In conclusion, this study identified ncPAP TENT5C as a new factor involved in the regulation of Ig production through ERassociated polyadenylation in $\mathrm{B}$ cell lineage in mice. Thus, we demonstrate the significance of cytoplasmic poly(A) tail homeostasis as an important regulatory level for B cell immune response.

\section{Methods}

Mice. Mice strains used in this study are listed in Supplementary Table 2. Mice strains: B6CBAF1;B6-TENT5C KO/Tar; B6CBAF1;B6-TENT5C Cat (D90N; D92N)/Tar; and B6CBAF1;B6-TENT5C-GFP/GFP/Tar were generated and genotyped by the Mouse Genome Engineering Facility (www.crisprmice.eu). Experimental mice originated from heterozygotic matings and they were cohoused 
Fig. 7 TENT5C affects the UPR response. a TENT5C is present in the ER fraction. Western blot analysis of Tent5c-GFP B cells (activated for 7 days), fractionation for ER, and cytosol. Arrow indicates the position of TENT5C-GFP, while asterisks indicate nonspecific bands. $\beta$-actin, HDLBP, SSR1, SSR3, PERK, CHOP, and GRP94 were used as fractionation controls. b Staining of the nucleus and the ER of activated B cells isolated from WT and Tent5c-GFP mice. c Flow cytometry analysis of ER-fluorescence intensity in CD138high cells and mature resting PC from WT and Tent5c KO at day 0 , and 4 days after activation. PC populations were analyzed based on CD138, CD19, CD45R, and ER-tracker. See the gating strategy in Supplementary Fig. 4. d Quantification of ER volume, measured as gMFI (geometric mean of fluorescence intensity) of ER-tracker, based on flow cytometry. gMFI for ER-tracker was checked for CD138high cells (left panel) and mature resting PC (right panel) at day 0 , and 4 days after activation $(n=5-9)$. e Percentage of mature PC 4 days after activation $(n=4)$. $\mathbf{f}$ qPCR analysis of Tent5c expression level after tunicamycin (Tu) treatment. WT B cells activated for 3 days, then treated with Tu in indicated concentrations for $5 \mathrm{~h}(n=6) . \mathbf{g}$ qPCR analysis of UPR markers expression in WT and Tent5c KO cells after ER stress induction with Tu in third day of activation (Xbp1 S-spliced, US- unspliced, T-total; $n=6$ or Chop $n=5$ ). $\mathbf{h}$ qPCR analysis of basal ER stress level in B cells WT and Tent5c KO in third day after activation $(n=5$, Chop $n=4)$. i Western blot analysis of UPR markers in WT and Tent5c KO cells after ER stress induction with Tu. The $\alpha$ tubulin was used as a loading control. $P$ values were calculated using two-way ANOVA with post hoc Bonferroni test $\mathbf{d}$, $\mathbf{g}$, two-tailed Mann-Whitney $U$ test e, two-tailed unpaired Student's $t$-test in $\mathbf{f}$, $\mathbf{h}$; not significant (ns); data are presented as mean values \pm SD; $n$-biological replicates. Source data: Supplementary Fig. 8 (7a, i) and Source Data file (7d-h).

littermates. Mice of both sex were sacrificed at age $12-16$ weeks (Tent5c KO and Tent $5 c$-GFP) and $48-56$ weeks (Tent5c Cat). All mice were bred in the animal house of Faculty of Biology, University of Warsaw. The immunization experiment was held at the animal house of Medical University of Warsaw. Mice were maintained in conventional conditions in open polypropylene cages filled with wood chip bedding (Rettenmaier). Environment was enriched with nest material and paper tubes. Mice were fed at libutum with standard laboratory diet (Labofeed $\mathrm{B}$, Morawski). Humidity in the rooms was kept at $55 \pm 10 \%$, temperature at $22{ }^{\circ} \mathrm{C} \pm$ $2{ }^{\circ} \mathrm{C}$, at least 15 air changes per hour, and light regime set at $12 \mathrm{~h} / 12 \mathrm{~h}$ (lights on from 6:00 to 18:00). Health monitoring was performed regularly at the IDEXX laboratory and reports are shown in Supplementary Table 3. The mice used in this study were naive and had no previous history of experimentation or exposure to drugs. The Tent5c KO mice strain was described previously ${ }^{21}$. The Tent5c Cterminal-GFP knock-in and Tent5c Cat animals were generated, and genotyped by the Mouse Genome Engineering Facility. All procedures were approved by the I Local Ethical Committee in Warsaw affiliated at Univeristy of Warsaw, Faculty of Biology (approval number WAW/176/2016) and II Local Ethical Committee in Warsaw, affiliated at Warsaw University of Life Sciences (approval number WAW2/159/2019), with the requirements of the EU (Directive 2010/63/EU) and Polish (Act number 266/15.01.2015) legislation.

Generation of Tent5c-GFP knock-in and Tent5c Cat mice. The Tent5c Cterminal-GFP knock-in mice line was generated using single-guide RNA (chimeric sgRNA). The sgRNA was synthesized using T7 RNA polymerase and DNA template obtained with mTENT5C_GFP_sgRNA_F and Universal_gRNA_rev primers (T7 promoter is underlined). All subsequent steps were performed as described previously $^{21}$. The dsDNA donor for in-frame C-terminal TEV-GFP knock-in, two $1 \mathrm{~kb}$ homology arms flanking Tent5c STOP codon were amplified from C57BL/6 J gDNA using mTent5C_TOPO-LF_1f/mTent5C_LF-TEV_1r and mTent5C_eGFPRF_1f/mTent5C_RF-TOPO_1r primer pairs. The TEV-eGFP coding sequence was amplified from pKK-TEV-eGFP plasmid using TEV_1F and mCherry_GFP_1R primers. Assembly of TEV-eGFP and $1 \mathrm{~kb}$ homology arms flanking Tent5c STOP codon was performed with TOPO Zero Blunt (Thermo Fisher Scientific). Next, we amplified $865 \mathrm{bp}$ fragment of TENT5C-TEV-eGFP donor flanked with $60 \mathrm{bp}$ homology arms from pTOPO/F46C/TEV-eGFP and mTent5C-GFP_short_1F/ mTent5C-GFP-short_1R primers. PCR product was purified with Agencourt AmpureXP magnetic beads (Beckman). Mice genotyping was carried out in PCR reaction using mTent5C_GFP_seqF and mTent5C_GFP_seqR primers, and Phusion HotStart II Polymerase (Thermo) and gDNA isolated from of mice ears or tails fragments with HotShot method or with Genomic Mini DNA isolation kit (A\&A Biotechnology). Tent5c catalytic mutants (Tent5c Cat), harboring two missense mutations D90N and D92N were created using the CRISPR/Cas9 method. sgRNA and SpCas9 mRNA sequences were identical to those used in creating Tent $5 c \mathrm{KO}$ and were described previously ${ }^{21}$. For introducing two missense mutations 85 nt TENT5C_catODN oligonucleotide was added to the microinjection mix at the final concentration of $1.25 \mathrm{pM}$. Tent $5 \mathrm{c}$ Cat mice were genotyped by Sanger sequencing of $585 \mathrm{bp}$ amplicons obtained with PCR using Fam46C_seq2F and Fam46C_seq2R primers. Chromatograms were analyzed using Mutation Surveyor 4.0 (SoftGenetics). All primers used for mice generation are listed in Supplementary Table 4.

Immunization of mice. To study the thymus-dependent (TD) antibody responses, 12 -week-old Tent $5 c \mathrm{KO}$ and WT littermates were immunized intraperitoneally with chicken OVA (Sigma-Aldrich) antigen $(50 \mu \mathrm{g} /$ mouse) mixed with complete Freud adjuvant (CFA, Invivogen; 1:1 vol:vol) at days 0 and 14. Mice were bled on indicated days via facial vein puncture. The concentrations of anti-OVA Igs were measured with the ELISA kit (Cayman Chemical, 500830) according to the manufacturer's recommendation. For TI antibody responses, 12 -week-old Tent $5 \mathrm{c}$ $\mathrm{KO}$ and WT littermates were immunized with TNP-LPS (50 $\mu \mathrm{g} /$ mouse, Bioresearch
Technologies, T-5065-5). Mice serum was collected at days 0, 7, and 14. The concentrations of anti-TNP Igs were measured with the ELISA kit (Life Diagnostics, Inc) according to the manufacturer's recommendation. The experiments were performed in accordance with the guidelines approved by the II Local Ethics Committee in Warsaw (approval no. WAW2/159/2019) and in accordance with the requirements of the EU (Directive 2010/63/EU) and Polish (Dz. U. poz. 266/ 15.01.2015) legislation.

Serum Igs ELISAs. Total concentrations of Igs of different isotypes in the sera collected from WT and Tent $5 \mathrm{c}$ KO mice were quantified using Mouse Ig Isotyping Ready-SET-Go (Invitrogen, 88-50630) and standards: IgA (Invitrogen, 39-5045065), IgG1 (Invitrogen, 39-50410-65), IgG2a (Invitrogen, 39-50420-65), IgG2b (Invitrogen, 39-50430-65), IgG3 (Invitrogen, 39-50440-65), and IgM (Invitrogen, 39-50470-65) according to the manufacturer's recommendation.

Tissue collection and blood analysis. Blood samples were collected terminally from the mandibular vein to EDTA or serum separator tubes. Complete blood counts, gel electrophoresis of proteins, and serum iron level analysis were performed at the Veterinary Diagnostic Laboratory LabWet in Warsaw (http://www. labwet.pl/) on the day of blood collection. SPEP analyses were performed using SAS-MX SP-10 Kit (Helena-Biosciences). Serum samples were diluted in the buffer in a ratio of 1:4 and proteins were separated at a constant voltage of $80 \mathrm{~V}$ through $25 \mathrm{~min}$. Gels were quantified with Platinum software V6 (Helena-Biosciences). All mice were sacrificed by cervical dislocation. Spleen and femur and tibia bones were isolated immediately. BM was isolated using centrifugation method ${ }^{52}$. BM was depleted of red blood cells using ACK lysis buffer (154.95 mM ammonium chloride, $10 \mathrm{mM}$ potassium bicarbonate, and $0.1 \mathrm{mM}$ EDTA).

Primary cell culture and ex vivo B cell activation. A single-cell suspension of splenocytes was obtained by mechanical tissue disintegration of the spleen through a $70 \mu \mathrm{m}$ cell strainer. Then, splenocytes were additionally depleted from red blood cells using ACK lysis buffer before separation. Naive B cells were isolated from spleen using immunomagnetic negative selection with EasySep ${ }^{\mathrm{mt}}$ Mouse B Cell Isolation Kit (Stemcell; 19854) and CD138high cells were isolated from spleen and BM, with EasySep Mouse CD138 Positive Selection Kit (Stemcell; 18957) according to the manufacturer's instructions. Primary cells were cultured in RPMI 1640 ATCC's modified (Invitrogen) supplemented with 15\% FBS (Invitrogen), $100 \mathrm{nM}$ 2-mercaptoethanol (Sigma), penicillin/streptomycin (Sigma), and activators or mitogens depending on the experiment: $20 \mathrm{ng} / \mathrm{ml} \mathrm{IL-4}$ (Peprotech; 214-14), $0.5 \mu \mathrm{g} /$ $\mathrm{ml}$ megaCD40L (Enzo Lifesciences; ALX-522-12-C010), $10 \mu \mathrm{g} / \mathrm{ml}$ anti-IgM (Thermo Fisher Scientific 16-5092-85), $20 \mu \mathrm{g} / \mathrm{ml}$ LPS (Santa Cruz Biotechnology; $\mathrm{sc}-3535), 1 \mu \mathrm{g} / \mathrm{ml}$ Pam3CSK4 (Invivogen; tlrl-pms), $10^{8}$ cells/ml HKLM (Invivogen, tlrl-hklm), $10 \mu \mathrm{g} / \mathrm{ml}$ Poly(I:C), HMW and LMW (Invivogen; tlrl-pic and tlrlpicw), $10 \mu \mathrm{g} / \mathrm{ml}$ LPS-EK standard (Invivogen; tlrl-peklps), $1 \mu \mathrm{g} / \mathrm{ml}$ FLA-ST (Invivogen; tlrl-epstfla), $100 \mathrm{ng} / \mathrm{ml}$ FSL1 (Invivogen; tlrl-fsl), $1 \mu \mathrm{g} / \mathrm{ml}$ ssRNA40/ LyoVec (Invivogen; tlrl-lrna40), and $1 \mu \mathrm{M}$ ODN1826 (Invivogen; tlrl-1826). In most experiments, cells were activated with $20 \mathrm{ng} / \mathrm{ml} \mathrm{IL}-4$ and $20 \mu \mathrm{g} / \mathrm{ml} \mathrm{LPS}$, unless stated otherwise.

Spleen histology and PC microscopy. For the histology of the spleen, animals were overdosed with ketamine/xylazine and perfused transcardially at $10 \mathrm{ml} / \mathrm{min}$ flow rate with PBS for 1 min following 4\% PFA in phosphate buffer (PB) for 2 min at room temperature (RT). Organs were dissected, postfixed in PFA for $2 \mathrm{~h}$ at RT and suffused with $30 \%$ sucrose solution in $\mathrm{PB}$ overnight at $4{ }^{\circ} \mathrm{C}$. For immunohistochemical staining, $10-\mu \mathrm{m}$ thick sections were cut with the cryostat, and sections were blocked $2 \mathrm{~h}$ with $10 \%$ rabbit serum and $1 \%$ BSA in TBS with $0.3 \%$ Triton X-100. Sections were incubated with primary antibodies anti-GFP from chicken (Abcam, ab13970) and anti-CD138 PE from rat (Clone 281-2) diluted 

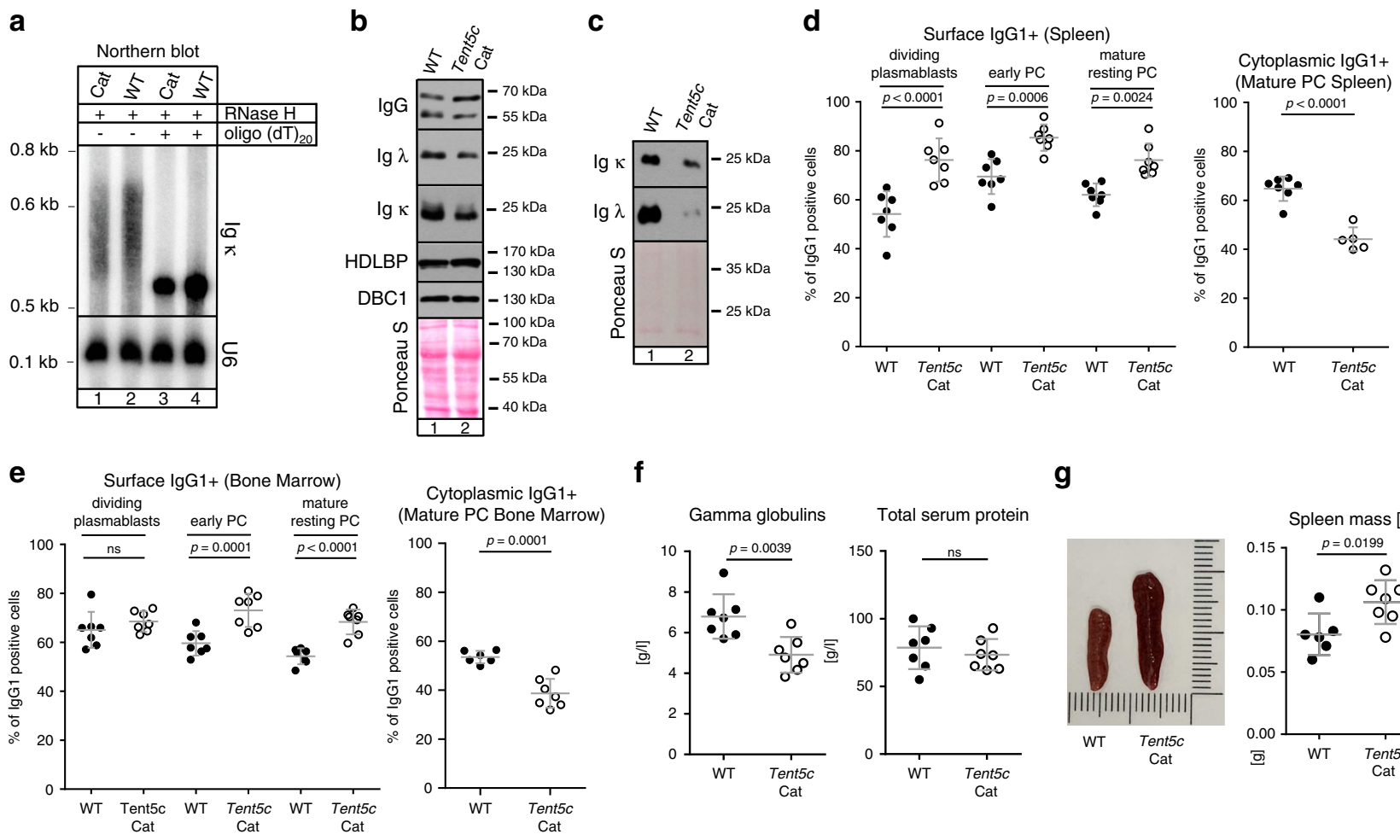

Cytoplasmic IgG1+

f

(Mature PC Bone Marrow)

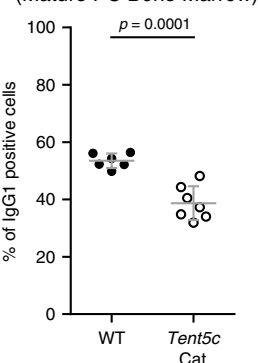

Gamma globulins Total serum protein

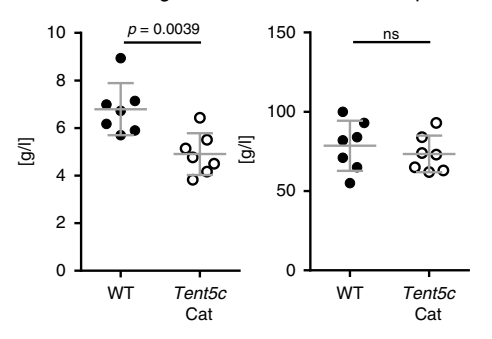

g

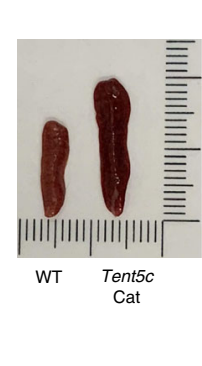

Spleen mass [g]

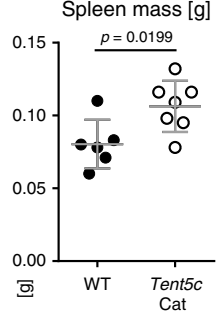

h

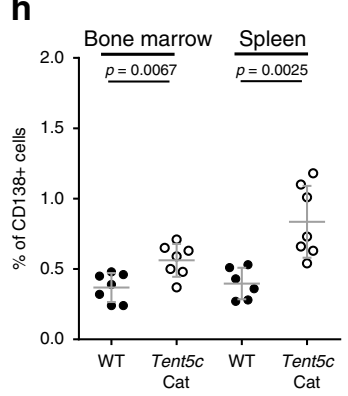

i
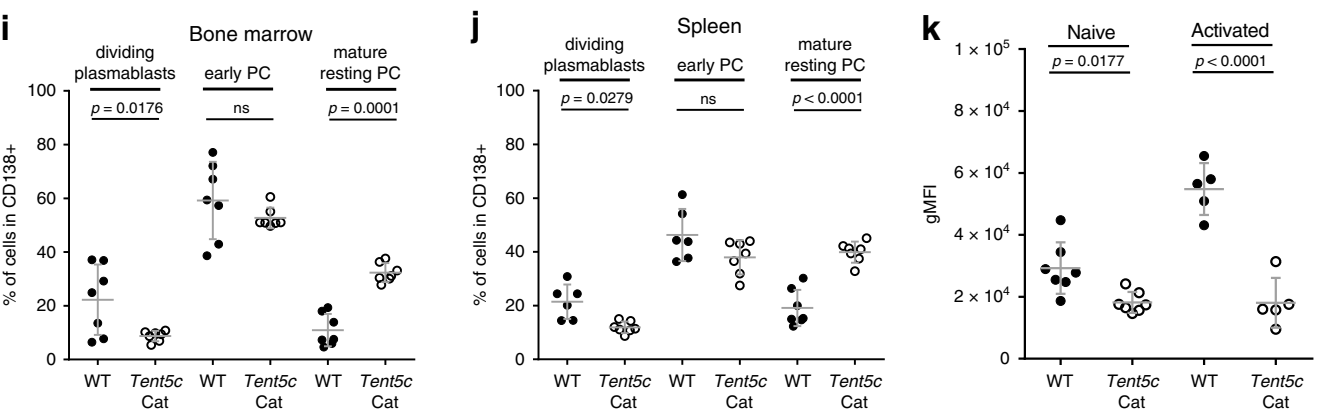

Fig. 8 Loss of TENT5C catalytic activity leads to humoral immune response deficiency. a The $\lg \kappa \mathrm{mRNA}$ poly(A) tail is reduced in Tent5c Cat B cells. Northern blot analysis of Ig $\kappa$ mRNA and U6 RNA (loading control) from Tent5c Cat and WT B cells activated for 7 days, treated with RNase $\mathrm{H}$ in the presence of oligo $(\mathrm{dT})_{20}$. b, $\mathbf{c}$ Western blot analysis of extracellular lgG heavy and light ( $\kappa$ and $\lambda$ ) chains, HDLBP, and DBC1 $\mathbf{b}$ or secreted to media lgs $\kappa$ and $\lambda$ light chains $\mathbf{c}$ from WT and Tent5c Cat B cells activated for 3 days. Ponceau S staining was used as a loading control. $\mathbf{d}$, e Percentage of cells positive for surface and cytoplasmic lgG1 isolated from spleen $\mathbf{d}$ or BM e $(\mathbf{d} n=7$ or $n=5$ for Cat in cytoplasmic lgG1+; e $n=7$ or $n=6$ for WT in cytoplasmic lgG1+). f Examination of blood serum gamma globulins and total protein levels in Tent5c Cat and WT by SPEP $(n=7)$. $\mathbf{g}$ Comparison of spleen mass in WT and Tent5c Cat mice (right panel; WT $n=6$, Cat $n=7$ ). Representative pictures are shown in the left panel. $\mathbf{h}$ Percentage of CD138-positive cells in BM and spleen; ( $n=7$ or $n=6$ for WT in spleen). $\mathbf{i}, \mathbf{j}$ Comparison of CD138-positive subpopulations: dividing plasmablasts, early PC, mature resting PC in WT, and Tent5c Cat isolated from BM $\mathbf{i}$ and spleen $\mathbf{j}(\mathbf{i} n=7 ; \mathbf{j} n=7$ or $n=6$ for WT dividing plasmablasts and early PC). $\mathbf{k}$ Quantification of ER volume, measured as gMFI (geometric mean of fluorescence intensity) of ER-tracker stained mature resting PC at day 0 (naive, $n=7$ ) and 4 days after activation (activated, $n=5$ ). $P$ values were calculated using two-way ANOVA with post hoc Bonferroni test $\mathbf{d}$, e, $\mathbf{i}$-k, two-tailed unpaired Student's $t$-test $\mathbf{d}$, e left panels, $\mathbf{f}, \mathbf{h}$, two-tailed unpaired Student's $t$-test with Welch correction $\mathbf{g}$; not significant (ns). Data are presented as mean values \pm SD; $n-$ biological replicates. Source data: Supplementary Fig. $8(8 a-c, g)$ and Source Data file $(8 d-f, h-k)$.

$1000 \times$ and $500 \times$, respectively, in blocking solution and developed with goat antiChicken Alexa 488 (Thermo Fisher Scientific, A-11039) with Hoechst diluted in blocking solution. After quenching and incubation with antibodies, sections were washed three times 5 min with TBS with Triton X-100 0.025\%.

Isolated CD138 high cells were stained using ER Staining Kit (Abcam; ab139482) according to the manufacturer's instruction with the following exceptions: Red Detection Reagent was diluted 2000x, Hoechst 33342 Nuclear Stain was diluted $500 \times$, and the staining time was shortened to $4 \mathrm{~min}$.

PCs and spleen section imaging were performed using a confocal system (Fluoview FV1000) equipped with a spectral detector (Olympus) and with a $60 \times$ oil objective with 1.40 aperture. Images were processed using ImageJ 1.52p software.

GST-elF4E ${ }^{\text {K119A }}$ purification. Chemocompetent $E$. coli BL21-CodonPlus-RIL strain (Stratagene) was transformed with plasmid pGEX-4T-3 carrying GST-eIF4EK119A.
Cells were preincubated in standard Luria-Broth (LB) medium (with $0.1 \mathrm{mg} / \mathrm{ml}$ ampicillin and $34 \mathrm{mg} / \mathrm{ml}$ chloramphenicol) overnight and then transferred to Auto Induction Media Super Broth Base Including Trace Elements (Formedium) supplemented with $2 \%$ glycerol, kanamycin $(50 \mathrm{mg} / \mathrm{ml})$, and chloramphenicol $(34 \mathrm{mg} / \mathrm{ml})$ and incubated for $48 \mathrm{~h}$ in $18^{\circ} \mathrm{C}$ with shaking $150 \mathrm{rpm}$. Bacteria were pelleted by centrifugation at $4500 \mathrm{rpm}$ for $15 \mathrm{~min}$ at $4^{\circ} \mathrm{C}$, frozen in liquid nitrogen and stored at $-20^{\circ} \mathrm{C}$. Pellet from $4 \mathrm{l}$ of culture was used for single purification. Pellet was resuspended in column buffer $\left(50 \mathrm{mM} \mathrm{N} \mathrm{N}_{2} \mathrm{HPO}_{4} \mathrm{pH} 7.5,150 \mathrm{mM} \mathrm{NaCl}, 1 \mathrm{mM}\right.$ EDTA) supplemented with $1 \mathrm{mM}$ DTT, $1 \%$ Triton X-100, $1 \mathrm{mM}$ PMSF, a protein inhibitor cocktail (20 nM pepstatin, $6 \mathrm{nM}$ leupeptin, $2 \mathrm{ng} / \mathrm{ml}$ chymostatin), and $50 \mu \mathrm{g} / \mathrm{ml}$ lysozyme, incubated for $20 \mathrm{~min}$ in $4^{\circ} \mathrm{C}$, then broken in a French pressure cell press MultisiFlex-C3 at 500 Bar. The homogenate was centrifuged in a Sorvall WX ULTRA SERIES ultracentrifuge, F37L rotor at $32000 \mathrm{rpm}$ for $45 \mathrm{~min}$ at $4{ }^{\circ} \mathrm{C}$. The supernatant was loaded on a $1 \mathrm{ml}$ column with Glutathione Sepharose $4 \mathrm{~B}$ resin (GE Healthcare; 17-0756-01), equilibrated by column buffer. ÄKTA Purifier system 
(GE Healthcare) was used for all purification steps. Unbound proteins were washed out with $20 \mathrm{CV}$ of column buffer. GST-eIF4E was collected during $5 \mathrm{CV}$ washing of elution buffer $\left(50 \mathrm{mM} \mathrm{Na}_{2} \mathrm{HPO}_{4} \mathrm{pH} 8.5,10 \mathrm{mM}\right.$ L-glutathione reduced, $1 \mathrm{mM}$ DTT). The elution fraction was mixed and diluted three times with water and loaded into the ion-exchange column (Resource S GE Healthcare; 17-1180-01), equilibrated by $50 \mathrm{mM} \mathrm{Na}_{2} \mathrm{HPO}_{4} \mathrm{pH}=8,100 \mathrm{mM} \mathrm{NaCl}$. GST-eIF4E was eluted by $0.1-1 \mathrm{M} \mathrm{NaCl}$ gradient. All purification steps were analyzed by SDS-PAGE.

RNA isolation. Total RNA was isolated from cells with TRIzol reagent (Thermo Fisher Scientific) according to the manufacturer's instructions, dissolved in nuclease-free water and stored at $-20^{\circ} \mathrm{C}$.

RNase $\mathbf{H}$ assay. Total RNA ( $20 \mu \mathrm{g})$ isolated from activated B cells, was mixed with $100 \mathrm{ng}$ of IgK_RNaseH oligo (which hybridizes to Ig $\kappa$ sequence and allow to shorten this transcript; sequence provided in Supplementary Table 5) and with (or without as a control) $100 \mathrm{ng}$ of oligo $(\mathrm{dT})_{20}$, heated for $1 \mathrm{~min}$ at $95^{\circ} \mathrm{C}$, and cooled down to $37^{\circ} \mathrm{C}$. Then, $10 \mu$ of $5 \times$ RH Reaction buffer (NEB) and $5 \mathrm{U}$ of RNase $\mathrm{H}$ (NEB) were added. Reactions were carried out for $45 \mathrm{~min}$ at $37^{\circ} \mathrm{C}$ and RNA were recovered by extraction with phenol/chloroform, precipitated, and analyzed using northern blots.

RT-qPCR. For the quantitative analysis, RNA was first treated with DNase (TURBO DNA-free Kit, Invitrogen; AM1907) for $30 \mathrm{~min}$ at $37^{\circ} \mathrm{C}$ and then reverse transcribed using SuperScript III (Invitrogen; 18080085) and oligo(dT) $)_{20}$ and random-primers (Thermo Fisher Scientific). The quantitative PCR was performed with Platinum SYBR Green qPCR SuperMix-UDG (Thermo Fisher Scientific; 11733046) using LightCycler 480 II (Roche) PCR device and appropriate primers listed in Supplementary Table 5. Gene expression for each sample was normalized to GAPDH. Differences were determined using the $2^{-\Delta \Delta C(t)}$ calculation.

Northern blotting. RNA samples were separated on $4 \%$ acrylamide gels containing $7 \mathrm{M}$ urea in $0.5 \times \mathrm{TBE}$ buffer and transferred to a Hybond $\mathrm{N}+$ membrane by electrotransfer in $0.5 \times$ TBE buffer. After transfer, membranes were stained with $0.03 \%$ methylene blue in $0.3 \mathrm{M} \mathrm{NaAc} \mathrm{pH} 5.3$ for $5 \mathrm{~min}$ at RT, scanned, and then destained with water. RNA was immobilized on membranes by $254 \mathrm{~nm}$ UV light using a UVP CL-1000 crosslinker. Radioactive probes were labeled with an $\alpha^{32} \mathrm{P}$ (dATP) with a DECAprime II DNA Labeling Kit (Thermo Fisher Scientific; AM1455). To obtain templates for probes labeling, PCR on cDNA from B cells activated with LPS and IL-4 for 7 days was conducted using primers listed in Supplementary Table 5. Alternatively, an oligo probe for U6 as a loading control was labeled with a $\gamma^{32} \mathrm{P}$ (ATP) with T4 PNK (NEB).

Membranes were pre-hybridized in PerfectHyb Plus Hybridization Buffer (Sigma, H7033) for $1 \mathrm{~h} 65^{\circ} \mathrm{C}$ and incubated with radioactive probes in PerfectHyb Plus Hybridization Buffer overnight $65^{\circ} \mathrm{C}$ (in case of oligo probe-at $37.5^{\circ} \mathrm{C}$ ). Then membranes were washed in $2 \times$ SSC with $0.1 \%$ SDS for $20 \mathrm{~min}, 0.5 \times$ SSC with $0.1 \%$ SDS for $20 \mathrm{~min}$ and $0.1 \times$ SSC with $0.1 \%$ SDS for 20 min, scanned with Fuji Typhoon FLA 7000 (GE Healthcare Life Sciences), and analyzed with Multi Gauge software V3.0 (Fujifilm).

mRNA enrichment with GST-elF4E ${ }^{\text {K119A }}$ protein. Purification was performed as described previously with some modifications ${ }^{25}$. Glutathione Sepharose $4 \mathrm{~B}$ resin was incubated with GST-eIF4E ${ }^{\mathrm{K} 119 \mathrm{~A}}$ protein in sterile PBS $(200 \mu \mathrm{l}$ resin per $200 \mu \mathrm{g}$ protein) for $1 \mathrm{~h}$ at RT with rotation. Then, the resin was washed two times with PBS and three times with buffer B (10 mM potassium PB, pH 8.0, $100 \mathrm{mM} \mathrm{KCl,} 2$ mM EDTA, 5\% glycerol (Sigma), 0.005\% Triton X-100 (Sigma), 6 mM DTT (A\&A Biotechnology), and $20 \mathrm{U} / \mathrm{mL}$ Ribolock RNase Inhibitor (Thermo Fisher Scientific, EO0381). A total of $100 \mu \mathrm{g}$ of total RNA, previously denaturated during $10 \mathrm{~min}$ at $70^{\circ} \mathrm{C}$, was mixed with the prepared resin and incubated for $1 \mathrm{~h}$ at RT on an immunoprecipitation rotor. Then, the resin was washed three times with buffer B, two times with buffer B supplemented with $0.5 \mathrm{mM}$ GDP (Sigma), and two times with buffer B without GDP. RNA was eluted from the resin by acid phenol: chloroform extraction and precipitated using 100\% ethanol (Merck), $3 \mathrm{M}$ sodium acetate, and GlycoBlue co-precipitant (Thermo Fisher Scientific).

Validation of the mRNA enrichment with GST-elF4EK119A protein. Total RNA $(150 \mu \mathrm{g})$ from HEK293T cells (which was a gift from Dr. Agnieszka Tudek) was subjected to mRNA enrichment with GST-eIF4E ${ }^{\mathrm{K} 119 \mathrm{~A}}$ protein as described above. Then, both total and purified RNA were either used for northern blot analysis or treated with DNase and $300 \mathrm{ng}$ was used for reverse transcription (as described above). To estimate mRNA enrichment and rRNA-removal efficiency cDNA was used for $\mathrm{qPCR}$ analysis, as described above.

RNA-seq. All experiments were done in triplicate, where a single replicate originated from Tent5c KO and WT littermates at age 12-15 weeks.

Cell culture and RNA retrieval: Naive B cells were isolated and cultured as described above. Subsequently, after isolation cells were activated by the addition of $20 \mathrm{ng} / \mathrm{ml} \mathrm{IL}-4$ (Peprotech) and $20 \mu \mathrm{g} / \mathrm{ml}$ LPS (Santa Cruz) to the medium, followed by 7 days of incubation. Finally, RNA was isolated as described above.
Library preparation: Total RNA was treated with DNase for $30 \mathrm{~min}$ in $37^{\circ} \mathrm{C}$ and $1 \mu \mathrm{g}$ of RNA was subjected to ribodepletion using a Ribo-Zero Gold rRNA-removal kit H/R/M (Illumina), according to the manufacturer's recommendations and spiked-in with external RNA (ERCC RNA Spike-In Mix, Thermo Fisher Scientific; 4456740). Strand-specific libraries were prepared using a dUTP protocol (KAPA Stranded RNA-Seq Library Preparation Kit, KAPA Biosystems; KK8401), according to the manufacturer. Library quality was assessed using chip electrophoresis performed on an Agilent 2100 Bioanalyzer (Agilent Technologies, Inc.). The libraries were sequenced using an Illumina NextSeq500 sequencing platform to an average number of $\sim 1.5 \times 10^{7}$ reads per library in the 75 -nt pairedend mode.

Nanopore direct RNA sequencing and polyadenylation analysis. RNA retrieval: Direct RNA sequencing was performed in triplicate. For two replicates, the same input RNA (batches 1 and 2) as for the RNA-seq experiment were used (described above). RNA $(100 \mu \mathrm{g})$ was subjected to mRNA enrichment with GST-eIF4E ${ }^{\mathrm{K} 119 \mathrm{~A}}$ protein (as described above), followed by the ribodepletion of $2.5 \mu \mathrm{g}$ RNA using a Ribo-Zero Kit (Illumina), according to the manufacturer's recommendations. The remaining replicates (batch 3) were prepared without ribodepletion step.

Library preparation and sequencing: Nanopore direct RNA libraries were prepared from $500 \mathrm{ng}$ of cap-enriched and ribodepleted mRNA with Direct RNA Sequencing Kit (ONT, SQK-RNA001 (for replicates 1-2) or SQK-RNA002 (replicate 3)). In the case of replicate 3, $4 \mu \mathrm{g}$ cap-enriched mRNA (without ribodepletion) was mixed with the $150 \mathrm{ng}$ of Saccharomyces cerevisiae oligo(dT)enriched RNA and $50 \mathrm{ng}$ of in vitro transcribed poly(A) standards. All remaining steps were performed according to the manufacturer's instructions, including the reverse transcription step. Sequencing was performed with the MinION device, MinKNOW 19.10.1 software, Flow Cell (Type R9.4.1; RevC (RevD for replicate 3)), and basecalled using Guppy 3.3.0 (ONT).

Actinomycin D treatment. B cells activated for 3 days were treated with actinomycin D (Sigma) at a final concentration of $5 \mu \mathrm{g} / \mathrm{ml}$ for $0-4 \mathrm{~h}$. Then, RNA was isolated with TRI reagent and subjected to RT-qPCR analysis as described above. Half-lives were estimated by nonlinear regression (one-phase decay analysis) in GraphPad Prism 6.

4-thiouridine labeling. B cells from $\mathrm{WT}$ and Tent $5 \mathrm{c} \mathrm{KO}$ mice were activated with LPS $(20 \mu \mathrm{g} / \mathrm{ml})$ and IL-4 $(20 \mathrm{ng} / \mathrm{ml})$ for 7 days. Then cells were treated with $4 \mathrm{sU}$ (Sigma, T4509) in a final concentration of $50 \mu \mathrm{M}$ for $1 \mathrm{~h}$ and cells were collected. RNA was isolated using TRI reagent and treated with TURBO DNase as described above. To minimize sample-to-sample variation, a previously prepared spike-in (RNA from Schizosaccharomyces pombe labeled with 4-thiouracil) was added to each sample. Then, RNA was biotinylated using MTSEA-biotin-XX (Biotium, 90066). The reaction containing $125 \mu \mathrm{l}$ of RNA, $10 \mu \mathrm{l}$ of $10 \times$ biotinylation buffer (100 mM HEPES pH 7.5, $10 \mathrm{mM}$ EDTA), and $10 \mu \mathrm{l}$ of $1 \mathrm{mg} / \mathrm{ml}$ MTSEA-biotin-XX was incubated in dark for $30 \mathrm{~min}$ on a rotating wheel. Then RNA was purified using Phase Lock Gel heavy tubes (5PRIME) and precipitated using 100\% ethanol, $3 \mathrm{M}$ sodium acetate, and $1 \mu \mathrm{l} \mathrm{GlycoBlue} \mathrm{(Invitrogen).} \mathrm{Biotinylated} \mathrm{RNA} \mathrm{was} \mathrm{iso-}$ lated with Dynabeads MyOne Streptavidin C1 beads (Invitrogen). To $240 \mu \mathrm{l}$ RNA,

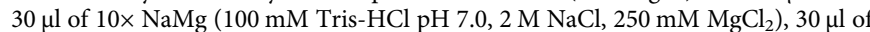
$1 \mathrm{M} \mathrm{NaPi}$ buffer $\mathrm{pH} 6.8$, and $3 \mu \mathrm{l}$ of $10 \%$ SDS were added. For one isolation, the 50 $\mu \mathrm{l}$ of beads were used. Beads were washed with $400 \mu \mathrm{l} \mathrm{NaMgPS}$ buffer $(10 \mathrm{mM}$ Tris$\mathrm{HCl}, \mathrm{pH} 7.0,200 \mathrm{mM} \mathrm{NaCl}, 25 \mathrm{mM} \mathrm{MgCl}, 100 \mathrm{mM} \mathrm{NaPi}$ buffer, $\mathrm{pH} 6.8,0.1 \%$ SDS) once and blocked with $10 \mu \mathrm{l}$ of $20 \mathrm{mg} / \mathrm{ml}$ glycogen (Invitrogen) in $200 \mu \mathrm{l}$ $\mathrm{NaMgPS}$ for $20 \mathrm{~min}$. Beads were washed with $400 \mu \mathrm{l} \mathrm{NaMgPS}$ buffer and then incubated with RNA for $30 \mathrm{~min}$ in dark on a rotating wheel. Beads were washed five times with $400 \mu \mathrm{l} \mathrm{NaMgPS}$ and once with TEN1000 (10 mM Tris-HCl, pH 7.5 $0,5 \mathrm{mM}$ EDTA, $1 \mathrm{M} \mathrm{NaCl}$ ). To elute RNA, beads were suspended in $100 \mu \mathrm{l}$ of 100 $\mathrm{mM}$ DTT, incubated for $5 \mathrm{~min}$, placed on magnetic stand, and supernatant was collected as nascent RNA fraction. The elution was repeated once. RNA was precipitated using $100 \%$ ethanol, $3 \mathrm{M}$ sodium acetate, $\mathrm{pH} 5.3$, and $1 \mu \mathrm{l}$ GlycoBlue (Invitrogen). Then nascent and total RNA fractions were subjected to RT-qPCR analysis as described above. Half-lives were estimated using equation: $t_{1 / 2}=-t_{\mathrm{L}} \times$ $\ln (2) / \ln (1 \text {-nascent/total })^{53}$.

Co-IP and MS. Activated with LPS $(20 \mu \mathrm{g} / \mathrm{ml})$ and IL- $4(20 \mathrm{ng} / \mathrm{ml})$ Tent $5 c$-GFP B cells were crosslinked with $1 \mathrm{mM}$ DSP (dithiobis(succinimidyl propionate); Invitrogen) for $1 \mathrm{~h}$ before stopping the reaction with $50 \mathrm{mM}$ Tris $\mathrm{pH}$ 8.0. After washing with PBS-supplemented $50 \mathrm{mM}$ Tris $\mathrm{pH} 8.0$, cells were flash-frozen in liquid nitrogen, thawed on ice, and incubated for $30 \mathrm{~min}$ at $4{ }^{\circ} \mathrm{C}$ with gentle rotation in $3 \mathrm{ml}$ LB buffer $(50 \mathrm{mM}$ Tris, $150 \mathrm{mM} \mathrm{NaCl}, 0.5 \%$ Triton X-100, $1 \mathrm{mM}$ DTT, supplemented with proteases, and phosphatase inhibitors; Invitrogen). Next, the lysates were sonicated for $30 \mathrm{~min}$ with a Bioruptor Plus (Diagenode), followed by clarification by centrifugation. Immunoprecipitations were performed using a GFP-Trap (ChromoTek; gtm-100). After $2 \mathrm{~h}$ of incubation, the beads were washed six times with LB buffer and finally, the proteins were eluted with $50 \mathrm{mM}$ glycine $\mathrm{pH}$ 2.8. After neutralization with Tris $\mathrm{pH}$ 8.0, proteins were precipitated with PRM reagent $(0.05 \mathrm{mM}$ pyrogallol red, $0.16 \mathrm{mM}$ sodium molybdate, $1 \mathrm{mM}$ sodium 
oxalate, $50 \mathrm{mM}$ succinic acid; pH 2.5 (Sigma-Aldrich)) prior to MS analysis in the Laboratory of MS, IBB PAS.

Western blotting. For western blot analysis, equal amount of cells were lysed with $0.1 \%$ NP40 in PBS supplemented with protease inhibitors and viscolase (A\&A Biotechnology, 1010-100) for $30 \mathrm{~min}$ in $37^{\circ} \mathrm{C}$ with shaking $600 \mathrm{rpm}$, then Laemmli buffer was added and samples were denatured for $10 \mathrm{~min}$ in $100^{\circ} \mathrm{C}$. For analysis of secreted proteins, the cell culture medium was collected and centrifuged twice 15 min $13,500 \mathrm{rpm}$, then the supernatant was collected, Laemmli buffer was added, and samples were denaturated for $10 \mathrm{~min}$ at $100^{\circ} \mathrm{C}$. Samples were separated on $12-15 \%$ SDS-PAGE gels, proteins were transferred to Protran nitrocellulose membranes (GE Healthcare), and then membranes were stained with $0.3 \% \mathrm{w} / \mathrm{v}$ Ponceau $\mathrm{S}$ in $3 \% \mathrm{v} / \mathrm{v}$ acetic acid and digitized. Membranes were incubated with $5 \%$ milk or 5\% BSA in TBST buffer according to the technical recommendations of the antibodies' suppliers for $1 \mathrm{~h}$ followed by incubation with specific primary antibodies (catalog and lot numbers are listed in the Supplementary Table 6 and Reporting Summary file) diluted 1:25,000 ( $\beta$-actin, Clone C4), 1:10,000 ( $\alpha$-tubulin, Clone DM1A), 1:5000 (HDLBP Bethyl, A303-971A; IgG Millipore, 401215; Ig $\lambda$ SCBT, sc-516132; Igk SCBT, sc-516102), 1:3000 (IL-6, Clone 10E5; GRP94, Clone H-212), 1:2000 (PERK, Clone C33E10; Xbp1, Clone EPR22004; TRAPa, Clone EPR5603; SSR3 Abcam, ab190936), or 1:1000 (Ire1, Clone 14C10; ATF6, Clone D4Z8V; CHOP, Clone D46F1; GFP ChromoTek, PABG1-100) overnight in $4{ }^{\circ} \mathrm{C}$. Membranes were washed three times in TBST buffer, incubated with HRPconjugated secondary antibodies: anti-mouse (Millipore, 401215) diluted 1:5000 and anti-rabbit (Millipore, 401393) diluted 1:3000, for $2 \mathrm{~h}$ at RT. Membranes were washed three times in TBST buffer and proteins were visualized by enhanced chemiluminescence acquired on X-ray film.

Flow cytometry. Splenocytes and BM were isolated as described above, and after depletion of red blood cells with ACK buffer cells were stained respectively. Designed staining panels were based on the "Flow cytometry tools for the study of B cell biology" (BD Pharmingen). The antibodies used for flow cytometry analysis are listed in Supplementary Table 6. Samples were measured with BD LSRFortessa ${ }^{\mathrm{m}}$ under FACS Diva Software v8.0.1 (BD) software control and analyzed using FlowJo (Data Analysis Software v10).

Surface staining of early developmental B cell stages. Cells $\left(1.5 \times 10^{6}\right)$ isolated from the BM or spleen were pelleted and incubated with Fc block (anti-CD16/32) for $10 \mathrm{~min}$ at RT. After washing with FACS buffer (0.2\% BSA in PBS), cells isolated from BM were stained with anti-CD19 BUV395 (Clone 1D3), anti-CD43 BV421 (Clone S7), anti-CD23 BV421 (Clone B3B4), anti-IgM FITC (Clone II/41), antiCD249 PE (Clone BP-1), anti-CD93 PE (Clone AA4.1), anti-IgD BV605 (Clone 1126 c.2a), anti-CD45R/B220 APC (Clone RA3-6B2), anti-CD24 PerCP Cy5.5 (Clone M1/69), and anti-CD21/CD35 PerCP Cy5.5 (Clone 7G6) antibodies for $30 \mathrm{~min}$ in $4{ }^{\circ} \mathrm{C}$, protected from light. In case, when two antibodies produced with BD Horizon technology were used in one staining panel, Brilliant Stain Buffer (BD Biosciences; 566349) was used to prepare the antibody mix. After staining, cells were washed with FACS buffer and then stained with LIVE/DEAD ${ }^{\text {sx }}$ Fixable Near-IR Dead Cell Stain Kit (Thermo Fisher Scientific; L34976) for $20 \mathrm{~min}$ in $4{ }^{\circ} \mathrm{C}$, protected from light. Finally, cells were washed and analyzed in terms of calculation PreProB, ProB, PreB, immature, transitional B, early and late mature B, T1, T2, T3, follicular $\mathrm{B}$ I and II, and marginal cell subsets (Marginal Zone and Marginal Zone Progenitor)

Surface staining of plasmablasts and PCs. Cells $\left(2.5 \times 10^{6}\right)$ isolated from the BM or spleen were incubated with Fc block anti-CD16/32, (Clone 2.4G2) for $10 \mathrm{~min}$ at RT, washed with FACS buffer and incubated with anti-CD19 BUV395 (Clone 1D3), anti-CD19 AF700 (Clone 1D3), anti-IgM FITC (Clone II/41), anti-IgA PE (Clone 11-44-2), anti-CD138 BV605 (Clone 281-2), anti-CD138 PE (Clone 281-2), anti-IgG1 AF647 (Thermo Fisher Scientific A-21240), and anti-CD45R/B220 PerCP Cy5.5 (Clone RA3-6B2) antibodies for $30 \mathrm{~min}$ in $4{ }^{\circ} \mathrm{C}$, protected from light. In case, when two antibodies produced with BD Horizon technology were used in one staining panel, Brilliant Stain Buffer was used to prepare the antibody mix. Next, cells were washed with FACS buffer and then stained with LIVE/DEAD ${ }^{\text {sw }}$ Fixable Near-IR or Violet Dead Cell Stain Kit (Thermo Fisher Scientific; L34964 for $20 \mathrm{~min}$ in $4^{\circ} \mathrm{C}$, protected from light. Finally, cells were washed and analyzed in terms of calculation dividing plasmablasts, early plasmocytes, and mature resting plasmocytes.

Staining of intracellular Igs. Cells $\left(2.5 \times 10^{6}\right)$ isolated from the BM or spleen were incubated with Fc block anti-CD16/32 (Clone 2.4G2) for $10 \mathrm{~min}$ at RT. After washing with FACS buffer (0.2\% BSA in PBS), cells isolated from the BM were stained with anti-CD19 BUV395 (Clone 1D3), anti-CD138 BV605 (Clone 281-2), and anti-CD45R/B220 PerCP Cy5.5 (Clone RA3-6B2) antibodies for $30 \mathrm{~min}$ in $4^{\circ}$ $\mathrm{C}$, protected from light. Cells were washed with FACS buffer and then incubated in Fixation/Permeabilization Solution for $20 \mathrm{~min}$ at $4{ }^{\circ} \mathrm{C}$. Upon washing in Wash/ Permeabilization solution, cells were stained with anti-IgM FITC (Clone II/41), anti-IgA PE (Clone 11-44-2), and anti-IgG1 AF647 (Thermo Fisher Scientific, A-
21240) for $30 \mathrm{~min}$ at $4^{\circ} \mathrm{C}$. After washing, cells were analyzed in terms of calculation intracellular/cytoplasmic intracellular Ig content.

Intracellular ER staining with for live-cell imaging. Cells $\left(1 \times 10^{6}\right)$ were resuspended in HSBB buffer and then were incubated with $0.75 \mu$ l of ER-Tracker ${ }^{\mathrm{TM}}$ Red (BODIPY ${ }^{\mathrm{s}}$ TR Glibenclamide, Thermo Fisher Scientific; E34250) for $30 \mathrm{~min}$ at $4^{\circ}$ $\mathrm{C}$, in the dark.

Splenocyte fractionation. The procedure was performed as described previously ${ }^{33,54}$. Briefly, activated B cells from Tent $5 c$-GFP knock-in mice were lysed in MTE buffer (270 mM D-mannitol, $10 \mathrm{mM}$ Tris pH 7.4, 0.1 mM EDTA, 1 mM PMSF) by homogenization monitored by microscopy. Extracts were cleared by sequential centrifugation at 700 and $15,000 \times g$ and subsequently were loaded on the top of the discontinuous sucrose gradient $(1.3 \mathrm{M}, 1.5 \mathrm{M}$, and $2 \mathrm{M}$ prepared in $10 \mathrm{mM}$ Tris $\mathrm{pH} 7.6,0.1 \mathrm{mM}$ EDTA) and ultracentrifuged at $152,000 \times \mathrm{g}$ for $70 \mathrm{~min}$ in an SW41 rotor (Beckman). The top layer was collected as cytosol fraction. ER fraction was collected as band at the interphase of $1.3 \mathrm{M}$ sucrose layer, diluted with additional MTE buffer and ultracentrifuged at $126,000 \times g$ for $45 \mathrm{~min}$ in MLA130 rotor (Beckman), and pellet was collected as purified ER, resuspended in PBS supplemented with proteases inhibitors and subsequently analyzed using western blot and antibodies against TRAPa (Clone EPR5603), SSR3 (Abcam, ab190936), HDLBP (Bethyl, A303-971A), and PERK (Clone C33E10, GRP94 (Clone H-212), CHOP (Clone D46F1), and GFP (ChromoTek, PABG1-100)).

ER stress analysis. WT and Tent $5 c$ KO B cells were activated with LPS $(20 \mu \mathrm{g} / \mathrm{ml})$ and IL-4 $(20 \mathrm{ng} / \mathrm{ml})$ for 3 days. Then, tunicamycin (Sigma) was added to a final concentration of 1 or $2.5 \mu \mathrm{g} / \mathrm{ml}$ for $5 \mathrm{~h}$ and cells were collected. RNA was isolated using TRI reagent (Sigma; T9424) according to the manufacturer's instructions and estimations of Xbpl splicing and expression level of Perk, Chop, Grp94, Ero1lB, and Ire $1 \alpha$ genes were carried out by RT-qPCR reactions as described above. Cells were also used for protein isolation and western blot analysis of UPR markers levels (XBP1, Clone EPR22004; IRE1, Clone 14C10; PERK, Clone C33E10; ATF6, Clone $\mathrm{D} 4 \mathrm{Z8V}$ ) as described above.

Differential expression analysis. Obtained Illumina sequencing reads were quality filtered using cutadapt (v. 1.18), to remove adapter sequences, low-quality fragments (minimum quality score was set to 20), and too short sequences (threshold set to $30 \mathrm{nt})^{55}$. Such quality-filtered reads were aligned to the mouse genome (GRCm38, downloaded from the ENSEMBL FTP site, release 94) using the STAR split read aligner (v. 2.6.1a) ${ }^{56}$. Counts for each transcript were collected using featureCounts from Subread package (v. 1.6.3), with options -Q $10-\mathrm{p}-\mathrm{B}-\mathrm{C}$ -s 2 -g gene_id -t exon and Gencode vM19 annotation ${ }^{57}$. Statistical analysis of differential expression was performed using the DESeq2 (v.1.22) Bioconductor package ${ }^{58}$, using default settings, correcting for the batch effect.

Poly(A) spike-in generation and evaluation. mRNA encoding barcoded eGFP with predefined poly(A) tails (A10, A30, A40, A60, A100, and A150) were generated in separate transcription in vitro reaction using SP6 RNA polymerase (NEB) according to the manufacturer's recommendation. mRNA preps were purified using AMPureXP (Beckman). DNA templates for the reaction were a kind gift from Prof. Eivind Valen (University of Bergen) and were described previously ${ }^{27}$.

Nanopore direct RNA sequencing. Nanopore reads were mapped to GencodeVM22 reference transcript sequences using Minimap 2.16 (ref. ${ }^{59}$ ). The poly(A) tail lengths for each read were estimated using Nanopolish 0.11 .1 polya function ${ }^{32}$ In subsequent analyses, only length estimates with QC tag reported by Nanopolish as PASS were considered. Statistical analysis was performed using functions provided in the NanoTail R package (https://github.com/pbrigf-ibb/nanotail, manuscript in preparation). In detail, we used the Generalized Linear Model approach with $\log 2$ (polya length) as a response variable, filtering out transcripts that had a low number of supporting reads in each condition $(<20)$. To correct for the batch effect, a replicate identifier was used as one of the predictors, in addition to the condition (Tent5c KO/WT) identifier. Collected $P$ values (for the condition effect) were adjusted for multiple comparisons using the Benjamini-Hochberg method. Transcripts were considered as having poly(A) tail significantly changed between analyzed conditions, if the adjusted $P$ value was $<0.05$, the absolute difference in the median tail length was at least 10 , and there were at least 20 supporting reads for each condition. All software and algorithms used in this study are listed in Supplementary Table 7

Poly(A) spike-ins analysis. The analysis was done as described previously ${ }^{27}$, with minor modifications. Briefly, Nanopore reads were first mapped against the eGFP sequence using minimap 2.16 (ref. ${ }^{59}$ ), then the eGFP start sequence was located within mapped reads using vMatchPattern from Biostrings. Next, the spike-in barcode was assigned by aligning the expected barcode sequences against the sequence preceding the eGFP start sequence using pairwise alignment function from Biostrings, with type local, match score set to 1, and gapOpening, gapExtension, and mismatch penalties set to $0,-1$, and -1 , respectively. The alignment 
score was normalized by dividing by the query length. The barcode with the highest normalized alignment score (and above a threshold of 0.3) was assigned to the read. Poly(A) lengths were estimated for all eGFP mapped reads with Nanopolish 0.11 .1 polya function and assigned to given spike-in based on barcode.

Statistics and reproducibility. Group size was based on the previous experience. No statistical method was used to predetermine sample size. Statistical analysis was conducted on data from three or more biologically independent experimental replicates. Statistical analysis of quantitative data was performed using Prism 6 software (GraphPad) unless otherwise stated. The statistical tests used in each instance are mentioned in the figure legends. All data were checked for normality using the Shapiro-Wilk test. Data are presented as scatter dot plots or bar plots, with mean values indicated and standard deviation shown as the error bars, as indicated in the figure legends, and individual data points are shown. Unless indicated otherwise " $n$ " represents the number of animals of each genotype used in a study. Most of the experiments were repeated at least twice, leading to comparable results with exception of RNase $\mathrm{H}$ assay, which was repeated once.The exact number of biological replicates used for statistical analysis is stated for every single experiment. Samples with clear technical failures during tissue harvesting, cells isolation, processing, or data collection throught flow cytometry or biochemical experiments were excluded from analyses.

\section{Data availability}

mRNA expression data are deposited in GEO with the accession code GSE132883. Nanopore direct RNA sequencing are deposited at European Nucleotide Archive with the accession code PRJEB33089. Raw data underlying figures are provided as a Source Data file or in Supplementary Fig. 8 and Supplementary Datasets, or are also available from the corresponding authors upon reasonable request.

\section{Code availability}

All custom code used in this study is deposited at https://github.com/pbrigf-ibb/nanotail.

Received: 26 July 2019; Accepted: 28 March 2020;

Published online: 27 April 2020

\section{References}

1. Wiest, D. L. et al. Membrane biogenesis during B cell differentiation: most endoplasmic reticulum proteins are expressed coordinately. J. Cell Biol. 110, 1501-1511 (1990).

2. Lynes, E. M. \& Simmen, T. Urban planning of the endoplasmic reticulum (ER): how diverse mechanisms segregate the many functions of the ER. Biochim. Biophys. Acta 1813, 1893-1905 (2011).

3. De Silva, N. S. \& Klein, U. Dynamics of B cells in germinal centres. Nat. Rev. Immunol. 15, 137-148 (2015).

4. Diaz-Munoz, M. D., Monzon-Casanova, E. \& Turner, M. Characterization of the B cell transcriptome bound by RNA-binding proteins with iCLIP. Methods Mol. Biol. 1623, 159-179 (2017).

5. Danger, R., Braza, F., Giral, M., Soulillou, J. P. \& Brouard, S. MicroRNAs, major players in B cells homeostasis and function. Front. Immunol. 5, 98 (2014).

6. Thai, T. H. et al. Regulation of the germinal center response by microRNA 155. Science 316, 604-608 (2007).

7. Vigorito, E. et al. microRNA-155 regulates the generation of immunoglobulin class-switched plasma cells. Immunity 27, 847-859 (2007).

8. Koralov, S. B. et al. Dicer ablation affects antibody diversity and cell survival in the B lymphocyte lineage. Cell 132, 860-874 (2008).

9. Xu, S., Guo, K., Zeng, Q., Huo, J. \& Lam, K. P. The RNase III enzyme Dicer is essential for germinal center B-cell formation. Blood 119, 767-776 (2012).

10. Goldfinger, M., Shmuel, M., Benhamron, S. \& Tirosh, B. Protein synthesis in plasma cells is regulated by crosstalk between endoplasmic reticulum stress and mTOR signaling. Eur. J. Immunol. 41, 491-502 (2011).

11. Houseley, J. \& Tollervey, D. The many pathways of RNA degradation. Cell 136, 763-776 (2009).

12. Siwaszek, A., Ukleja, M. \& Dziembowski, A. Proteins involved in the degradation of cytoplasmic mRNA in the major eukaryotic model systems. RNA Biol. 11, 1122-1136 (2014).

13. Hrit, J. et al. In vitro analysis of RNA degradation catalyzed by deadenylase enzymes. Methods Mol. Biol. 1125, 325-339 (2014).

14. Takagaki, Y. \& Manley, J. L. Levels of polyadenylation factor CstF-64 control IgM heavy chain mRNA accumulation and other events associated with B cell differentiation. Mol. Cell 2, 761-771 (1998).

15. Peng, Y., Yuan, J., Zhang, Z. \& Chang, X. Cytoplasmic poly(A)-binding protein 1 (PABPC1) interacts with the RNA-binding protein hnRNPLL and thereby regulates immunoglobulin secretion in plasma cells. J. Biol. Chem. 292, 12285-12295 (2017).

16. Enders, A. et al. Zinc-finger protein ZFP318 is essential for expression of $\operatorname{IgD}$, the alternatively spliced Igh product made by mature B lymphocytes. Proc. Natl Acad. Sci. USA 111, 4513-4518 (2014).

17. Pioli, P. D., Debnath, I., Weis, J. J. \& Weis, J. H. Zfp318 regulates IgD expression by abrogating transcription termination within the Ighm/Ighd locus. J. Immunol. 193, 2546-2553 (2014).

18. Friday, A. J. \& Keiper, B. D. Positive mRNA translational control in germ cells by initiation factor selectivity. Biomed. Res. Int. 2015, 327963 (2015)

19. Kuchta, K., Knizewski, L., Wyrwicz, L. S., Rychlewski, L. \& Ginalski, K. Comprehensive classification of nucleotidyltransferase fold proteins: identification of novel families and their representatives in human. Nucleic Acids Res. 37, 7701-7714 (2009).

20. Kuchta, K. et al. FAM46 proteins are novel eukaryotic non-canonical poly(A) polymerases. Nucleic Acids Res. 44, 3534-3548 (2016).

21. Mroczek, S. et al. The non-canonical poly(A) polymerase FAM46C acts as an onco-suppressor in multiple myeloma. Nat. Commun. 8, 619 (2017).

22. Zhu, Y. X. et al. Loss of FAM46C promotes cell survival in myeloma. Cancer Res. 77, 4317-4327 (2017)

23. Feng, Y., Zhang, Y., Ying, C., Wang, D. \& Du, C. Nanopore-based fourthgeneration DNA sequencing technology. Genomics Proteomics Bioinformatics 13, 4-16 (2015)

24. Garalde, D. R. et al. Highly parallel direct RNA sequencing on an array of nanopores. Nat. Methods 15, 201-206 (2018).

25. Bajak, E. Z. \& Hagedorn, C. H. Efficient 5' cap-dependent RNA purification: use in identifying and studying subsets of RNA. Methods Mol. Biol. 419, 147-160 (2008).

26. Choi, Y. H. \& Hagedorn, C. H. Purifying mRNAs with a high-affinity eIF4E mutant identifies the short 3' poly(A) end phenotype. Proc. Natl Acad. Sci. USA 100, 7033-7038 (2003).

27. Krause, M. et al. tailfindr: alignment-free poly(A) length measurement for Oxford Nanopore RNA and DNA sequencing. RNA 25, 1229-1241 (2019).

28. Temperley, R. J., Wydro, M., Lightowlers, R. N. \& Chrzanowska-Lightowlers, Z. M. Human mitochondrial mRNAs-like members of all families, similar but different. Biochimic. Biophys. Acta 1797, 1081-1085 (2010).

29. Tomecki, R., Dmochowska, A., Gewartowski, K., Dziembowski, A. \& Stepien, P. P. Identification of a novel human nuclear-encoded mitochondrial poly(A) polymerase. Nucleic Acids Res. 32, 6001-6014 (2004).

30. Borowski, L. S., Szczesny, R. J., Brzezniak, L. K. \& Stepien, P. P. RNA turnover in human mitochondria: more questions than answers? Biochim. Biophys. Acta 1797, 1066-1070 (2010).

31. Legnini, I., Alles, J., Karaiskos, N., Ayoub, S. \& Rajewsky, N. FLAM-seq: fulllength mRNA sequencing reveals principles of poly(A) tail length control. Nat. Methods 16, 879-886 (2019).

32. Workman, R. E. et al. Nanopore native RNA sequencing of a human poly(A) transcriptome. Nat. Methods 16, 1297-1305 (2019).

33. Williamson, C. D., Wong, D. S., Bozidis, P., Zhang, A. \& Colberg-Poley, A. M. Isolation of endoplasmic reticulum, mitochondria, and mitochondriaassociated membrane and detergent resistant membrane fractions from transfected cells and from human cytomegalovirus-infected primary fibroblasts. Curr. Protoc. Cell Biol. 68, 327 21-33 (2015).

34. Warkocki, Z., Liudkovska, V., Gewartowska, O., Mroczek, S. \& Dziembowski, A. Terminal nucleotidyl transferases (TENTs) in mammalian RNA metabolism. Philos. Trans. R. Soc. Lond. B Biol. Sci. 373, 20180162 (2018).

35. Roake, C. M. et al. Disruption of telomerase RNA maturation kinetics precipitates disease. Mol. Cell 74, 688-700 (2019).

36. Chang, H., Lim, J., Ha, M. \& Kim, V. N. TAIL-seq: genome-wide determination of poly(A) tail length and 3' end modifications. Mol. Cell 53, 1044-1052 (2014)

37. Harrison, P. F. et al. PAT-seq: a method to study the integration of 3'-UTR dynamics with gene expression in the eukaryotic transcriptome. RNA 21, 1502-1510 (2015)

38. Nicholson, A. L. \& Pasquinelli, A. E. Tales of detailed poly(A) tails. Trends Cell Biol. 29, 191-200 (2019).

39. Welch, J. D. et al. EnD-Seq and AppEnD: sequencing 3' ends to identify nontemplated tails and degradation intermediates. RNA 21, 1375-1389 (2015).

40. Woo, Y. M. et al. TED-Seq identifies the dynamics of Poly(A) length during ER stress. Cell Rep. 24, 3630-3641 e3637 (2018).

41. Liu, Y., Nie, H., Liu, H. \& Lu, F. Poly(A) inclusive RNA isoform sequencing (PAIso-seq) reveals wide-spread non-adenosine residues within RNA poly(A) tails. Nat. Commun. 10, 5292 (2019).

42. Shi, W. et al. Transcriptional profiling of mouse B cell terminal differentiation defines a signature for antibody-secreting plasma cells. Nat. Immunol. 16, 663-673 (2015). 
43. Pasare, C. \& Medzhitov, R. Control of B-cell responses by Toll-like receptors. Nature 438, 364-368 (2005).

44. Kang, S. M. et al. MyD88 plays an essential role in inducing B cells capable of differentiating into antibody-secreting cells after vaccination. J. Virol. $\mathbf{8 5}$, 11391-11400 (2011)

45. Kirk, S. J., Cliff, J. M., Thomas, J. A. \& Ward, T. H. Biogenesis of secretory organelles during B cell differentiation. J. Leukoc. Biol. 87, 245-255 (2010).

46. Liu, B. \& Li, Z. Endoplasmic reticulum HSP90b1 (gp96, grp94) optimizes Bcell function via chaperoning integrin and TLR but not immunoglobulin. Blood 112, 1223-1230 (2008).

47. Braakman, I. \& Hebert, D. N. Protein folding in the endoplasmic reticulum. Cold Spring Harb. Perspect. Biol. 5, a013201 (2013).

48. Schuck, S., Prinz, W. A., Thorn, K. S., Voss, C. \& Walter, P. Membrane expansion alleviates endoplasmic reticulum stress independently of the unfolded protein response. J. Cell Biol. 187, 525-536 (2009).

49. Gass, J. N., Gunn, K. E., Sriburi, R. \& Brewer, J. W. Stressed-out B cells? Plasma-cell differentiation and the unfolded protein response. Trends Immunol. 25, 17-24 (2004).

50. Reimold, A. M. et al. Plasma cell differentiation requires the transcription factor XBP-1. Nature 412, 300-307 (2001).

51. Tellier, J. et al. Blimp-1 controls plasma cell function through the regulation of immunoglobulin secretion and the unfolded protein response. Nat. Immunol. 17, 323-330 (2016).

52. Amend, S. R., Valkenburg, K. C. \& Pienta, K. J. Murine hind limb long bone dissection and bone marrow isolation. J. Vis. Exp. 110, 53936 (2016).

53. Russo, J., Heck, A. M., Wilusz, J. \& Wilusz, C. J. Metabolic labeling and recovery of nascent RNA to accurately quantify mRNA stability. Methods $\mathbf{1 2 0}$, 39-48 (2017).

54. Zhu, H. et al. Ufbp1 promotes plasma cell development and ER expansion by modulating distinct branches of UPR. Nat. Commun. 10, 1084 (2019).

55. Martin, M. Cutadapt removes adapter sequences from high-throughput sequencing reads. EMBnet J. 17, 3 (2011).

56. Dobin, A. et al. STAR: ultrafast universal RNA-seq aligner. Bioinformatics 29, 15-21 (2013).

57. Liao, Y., Smyth, G. K. \& Shi, W. featureCounts: an efficient general purpose program for assigning sequence reads to genomic features. Bioinformatics 30, 923-930 (2014).

58. Love, M. I., Huber, W. \& Anders, S. Moderated estimation of fold change and dispersion for RNA-seq data with DESeq2. Genome Biol. 15, 550 (2014).

59. Li, H. Minimap2: pairwise alignment for nucleotide sequences. Bioinformatics 34, 3094-3100 (2018).

\section{Acknowledgements}

We would like to thank Maximilian Krause and Eivind Valen (University of Bergen) for DNA templates encoding ONT spike-ins, Aleksander Chlebowski for microscopy assistance, Dominik Cysewski for high-resolution MS analyses, Marcin Szpila for assistance in coordination of animal housework, Agnieszka Tudek for providing RNA from HEK293T cell line and 4-thiouracil-labeled S. pombe cells, and Janina Durys for the editing of the manuscript and all laboratory members for stimulating discussions. The equipment from www.ibb.waw.pl/en/services/mass-spectrometry-lab was sponsored in part by the Centre for Preclinical Research and Technology (CePT), a project co- sponsored by European Regional Development Fund and Innovative Economy, The National Cohesion Strategy of Poland. This work was funded by NCN OPUS14, UMO2017/27/B/NZ2/01234 (to S.M.) and co-supported by NCN Harmonia10 UMO-2013/10/ M/NZ4/00299 (to A.D.), FNP TEAM TECH CORE FACILITY/2017-4/5 (to A.D.), and "Regional Initiative of Excellence" program by the Ministry of Science and Higher Education 013/RID (to J. Golab).

\section{Author contributions}

S.M. and A.D. developed and directed the studies, A.B. and S.M. carried out the majority of the biochemical and cell line experiments, M.K.-K. performed all flow cytometry analyses, P.S.K. performed all bioinformatics analyses, O.G. analyzed mice blood, performed nonimmunized serum ELISA tests, participated in localization studies, and coordinated work of the animal house, B.T. performed tissue immunostaining, K.K. purified the eIF4E protein, D.N. and J. Golab immunized mice and performed immunized serum ELISA tests, J. Gruchota prepared CRISPR reagents and genotyped mice, and E.B. generated transgenic animals. S.M., A.D., P.S.K., A.B., O.G., and M.K.-K.wrote the manuscript.

\section{Competing interests}

The authors declare no competing interests.

\section{Additional information}

Supplementary information is available for this paper at https://doi.org/10.1038/s41467020-15835-3.

Correspondence and requests for materials should be addressed to A.D. or S.M.

Peer review information Nature Communications thanks Cornelia de Moor and the other, anonymous, reviewer(s) for their contribution to the peer review of this work. Peer review reports are available.

Reprints and permission information is available at http://www.nature.com/reprints

Publisher's note Springer Nature remains neutral with regard to jurisdictional claims in published maps and institutional affiliations.

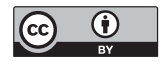

Open Access This article is licensed under a Creative Commons Attribution 4.0 International License, which permits use, sharing, adaptation, distribution and reproduction in any medium or format, as long as you give appropriate credit to the original author(s) and the source, provide a link to the Creative Commons license, and indicate if changes were made. The images or other third party material in this article are included in the article's Creative Commons license, unless indicated otherwise in a credit line to the material. If material is not included in the article's Creative Commons license and your intended use is not permitted by statutory regulation or exceeds the permitted use, you will need to obtain permission directly from the copyright holder. To view a copy of this license, visit http://creativecommons.org/ licenses/by/4.0/.

(C) The Author(s) 2020 